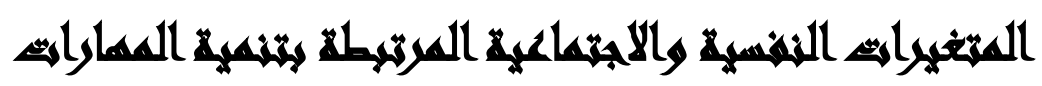

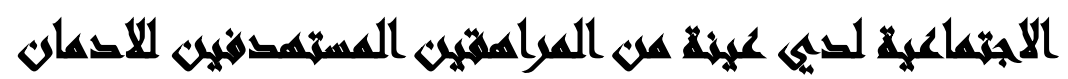

[iv]

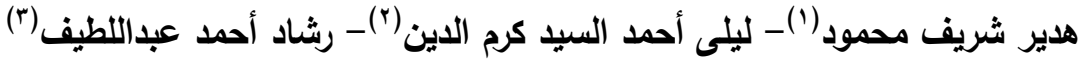

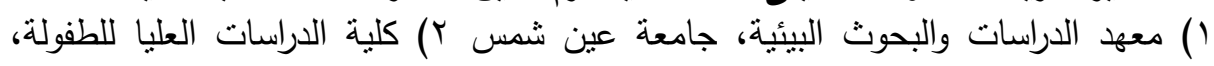
جامعة عين شمس r) كلية خدمة اجتماعية، جامعة حلوان

\section{المسرخلمس}

تعتبر مشكلة تعاطي المواد المتعددة للمخدرات من المشكلات النفسية الاجتماعية

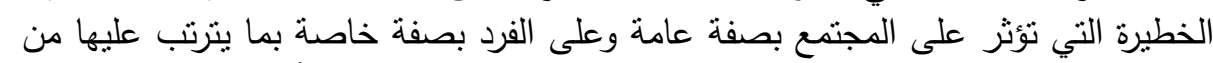

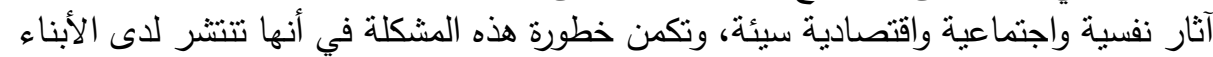

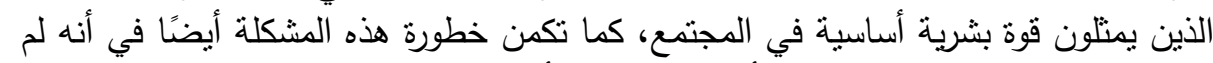

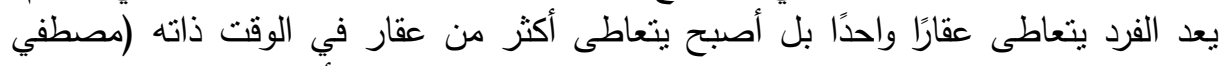

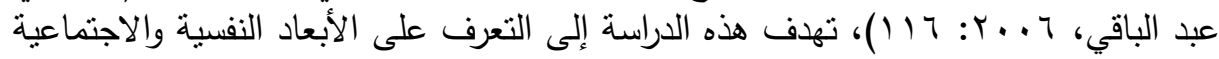

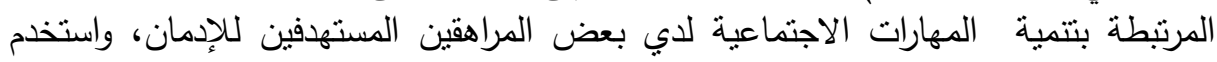

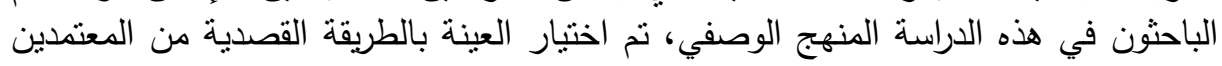

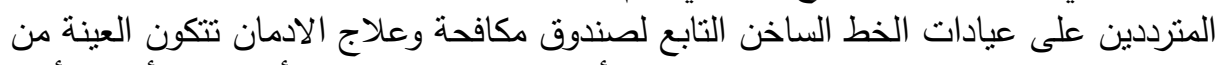

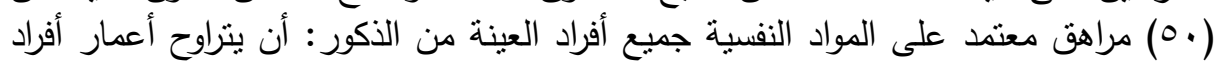

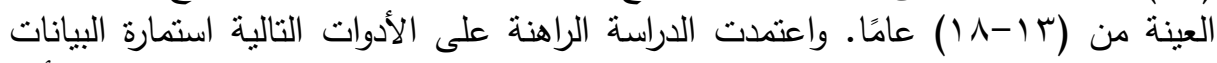

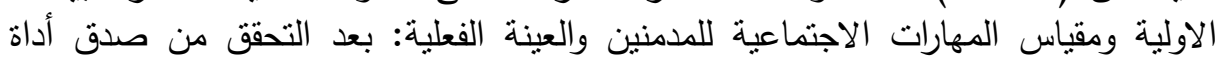

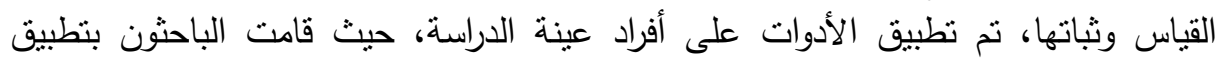
(0. ) مقياس إجمالي عدد العينة.

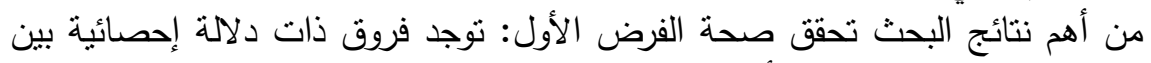

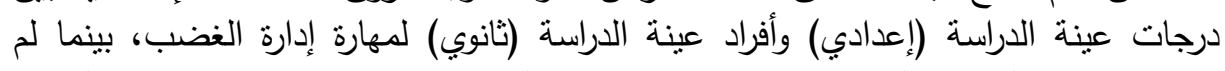

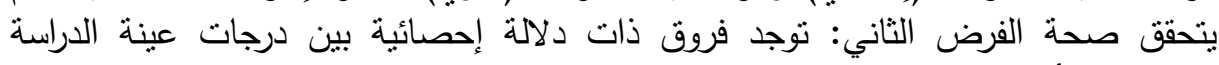

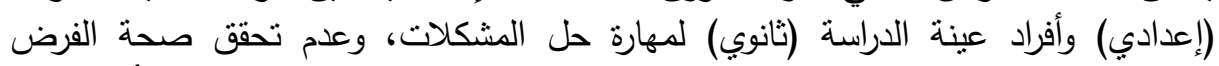

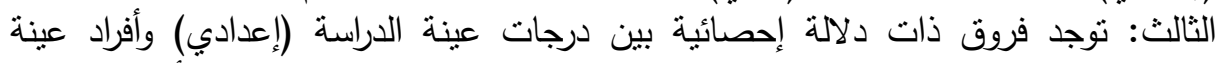

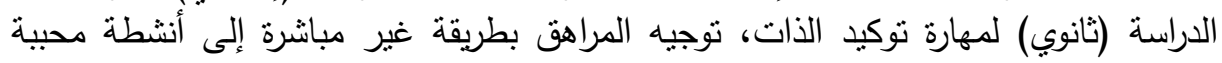

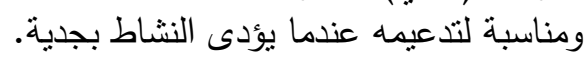

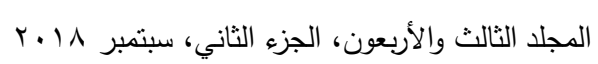


ويوصي الباحثون بتدريب المراهق المدمن على التعبير عن مشاعره تجاه أبي مشكلة

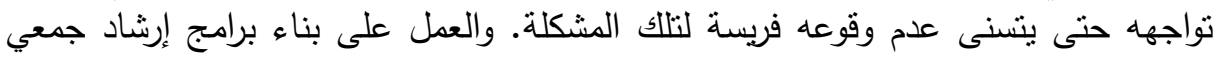

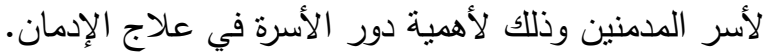
الكلمات المفتاحية: المهارات الاجتماعية، الادمان، المراهين الأهين، المتغيرات النفسية ، المتغيرات

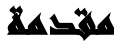

إن فثل الإنسان، في السبطرة على مخدر من المخدرات أو التحكم في نشاط من الأنشطة، يكاد بحبط كل المحاولات التي يستهدف بها ذلك الثخص السيطرة فلى على اللى الاعنماد على ذلك المخدر أو ذلك النشاط. السبب في ذلك أن أصل الإدمان وأساسه ليس في المخدر أو النشاط وإنما هو مجرد شوق ورغبة في تغيير الحالة النفسية، من هنا يصبح التعافي في المحصلة النهائية، تغييرا لأسلوب الحياة الذي نسير عليه حياة المدمن (المعتمد)، أو أن شئت فئت فئن فقل: التعافي هو التخلص من أسلوب حياة الإدمان. ثم جانبا آخر تتطوي عليه مشكلة الاعتماد وهو الجانب الذي يركز على أبعاد التكوين

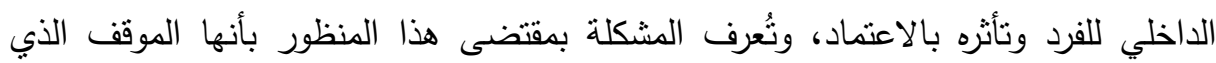

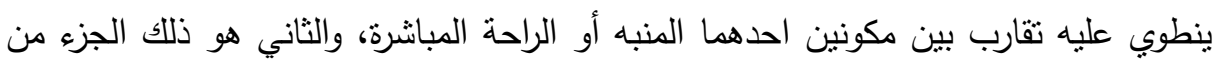
الفرد الذي يترتب عليه هذا التعاطي، والذي يتحدد وجوده من خلال إدراكات الأفراد الذين قاموا

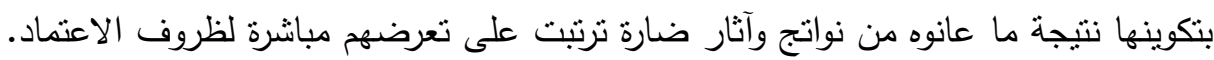

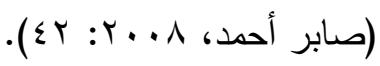
ويعتبر الاعتماد بين الأطفال والثباب من أكثر الأمور انتثارا بين الطبقات الاجتماعية

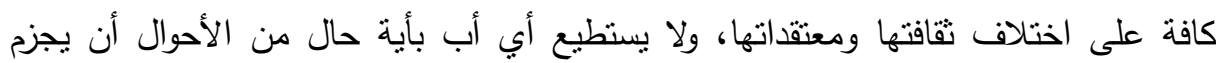

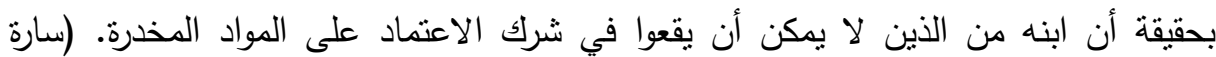

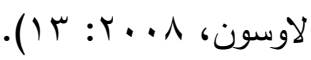

وفقًا لأحدث البيانات المتاحة، لم يحدث سوي القليل من التغيرٌ في الحالة العالمية العامة المتعلقة بإنتاج المخدرات غير المشروعة وتعاطيها وعواقبها الصحية. ومازالت العواقب

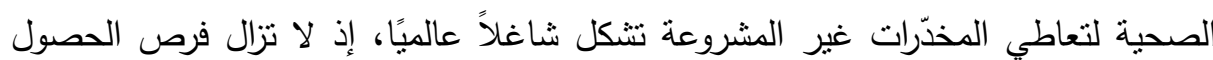




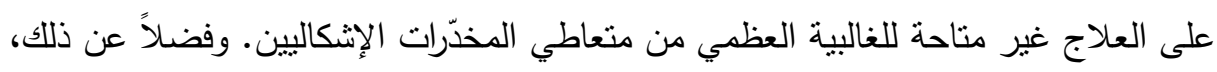

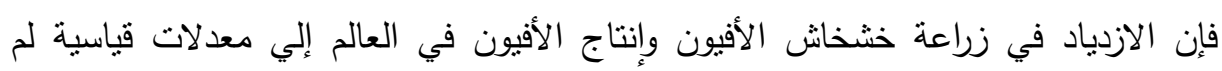

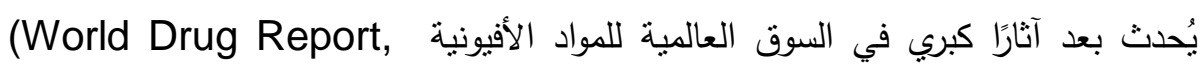

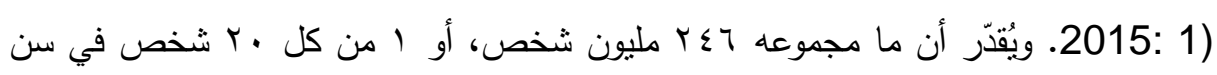

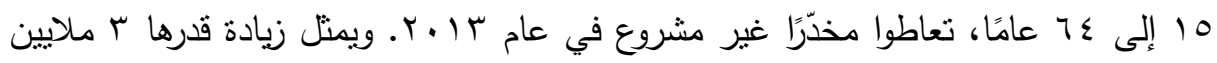
شخص عن السنة السابقة، ولكن معدل تعاطي المخدّرات غير المشروعة بقي ثابنًا في الواقع بسبب ازدياد عدد سكان العالم (المرجع السابق، العن ).

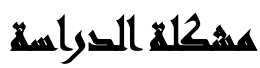

تعتبر مشكلة تعاطي المواد المخدرة من المشكلات النفسية الاجتماعية الخطيرة التي تؤثر على المتمع بصفة عامة وعلى الفرد بصفة خاصة بما يترتب عليها من آثار نفسية واجنماعية

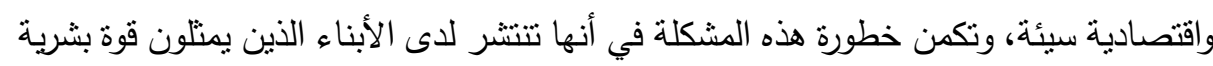

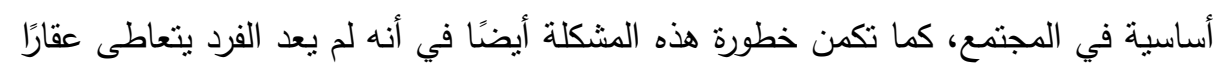

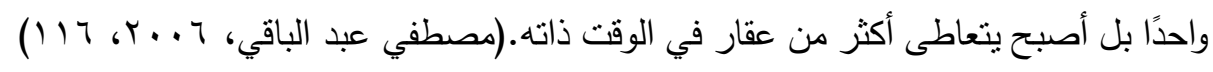
تتلخص مشكلة الدراسة في محاولة التعرف على المتغيرات النفسية والاجتماعية المرتبطة لونة بتتمية المهارات الاجتماعية لدى بعض المراهقين المعتمدين علي الإدمان حتي يستطيعوا استخدامها بعد ذللك كخط دفاع من الانجراف فى براثن الادمان.

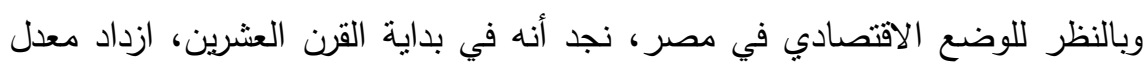
تعاطي الهيروين والكوكايين في مصر ، لكن ظل مخدر الحشيش والبانجو هما الأكثر شيوعًا،

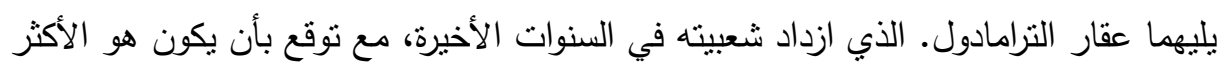

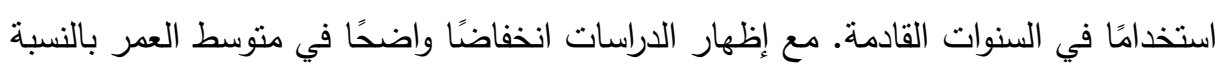
لسن بداية تعاطي المخدرات، كونه الأكثر شيوعًا بين الذكور ، وهذا يرتبط بمتغيرات ديموجرافية أخري تؤثر على مدي وطبيعة انتشار التعاطي.

Fawzi, 2010) 
وقد أظهرت دراسات تالية انخفاضًا واضحًا في متوسط العمر بالنسبة لسن بداية تعاطي المخدرات، كما أنه أكثر شيوعًا في الذكور عن الإناث. ويرتبط كذللك بمتغيرات ديموجرافية أخري تؤثز على مدي وطبيعة انتشار التعاطي، كما أظهرت الدراسات أيضًا الازدياد التدريجي لتعاطي الكحوليات في مصر ، مع توقع بأن يكون أكثر استخدامًا من السنوات القليلة المقبلة.

(UNODC, 1999; Okasha, 2001)

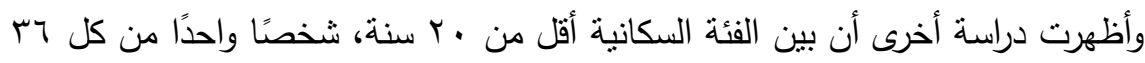

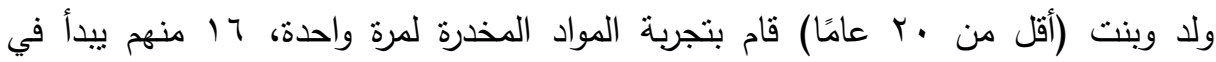

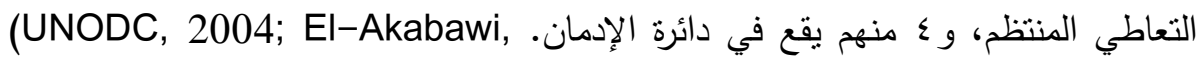

وقد وجد في دراسة خاصة بالإدمان بين المراهقين، أن منوسط بداية التدخين كانت

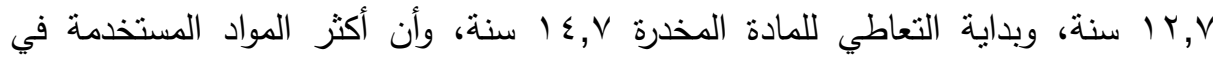
التعاطي كانت الحشيش ثم الكحوليات والبانجو والمهدئات ثم الهيروين وأخيرًا أقراص الترامادول. (ممتاز عبد الوهاب وآخرون، 7 . . r).

\section{سوأال الدواسمة}

ويالتالي يمكن صياغة سؤال الدراسة كالتالي: ما هي المتغيرات النفسية والاجتماعية اللازمة لتتمية المهارات الاجتماعية لدي المراهقين المستهدفين لتعاطي المواد المخدرة؟

\section{هنوضر القراسلة}

• توجد فروق دالة احصائيا بين عينة من المراهقين المتعاطين فى المرحلة الاعدادية ووعينة

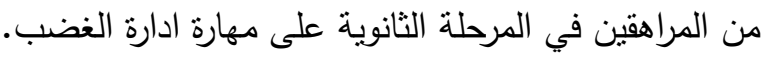
• توجد فروق دالة احصائيا بين عينة من المراهقين المتعاطين فى المرحلة الاعدادية ووعينة من المراهقين في المرحلة الثانوية على مهارة توكيد الذات. • توجد فروق دالة احصائيا بين عينة من المراهقين المتعاطين فى المرحلة الاعدادية ووعينة من المراهقين في المرحلة الثانوية على مهارة حل المشكلات. 


\section{هم:هن الصواسمة}

تهدف هذه الدراسة الى التعرف على الابعاد النفسية والاجتماعية المرتبطة بتتمية المهارات الاجتماعية لدي بعض المراهقين المستهدفين للإدمان.

\section{أهمي التوراسم}

تعتبر هذه الدراسة من الدراسات الوصفية التى تهنم بمعرفة الابعاد النفسية والاجتماعية

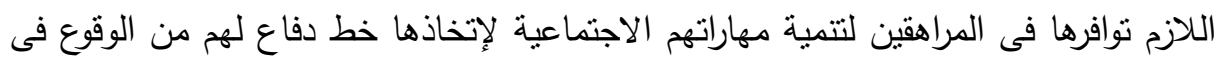
مخاطر التعاطي أو الإدمان. يمكن تحديد الأهمية التطبيقية فى هذه الادمان.

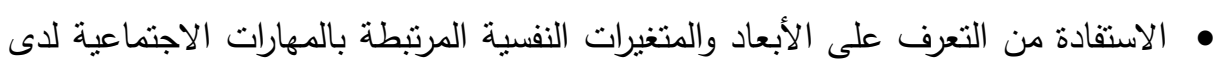
المراهقين المعتمدين علي الإدمان في تتمية المهارات لديهم. • الكثف عن المتغيرات النفسية المرتبطة بتعاطى المخدرات وتحديدها للوقوف عليها لتجنب المراهقين الوقوع في تعاطى المخدرات بسببها. • مساعدة المختصين في البرامج الوقائية في عمل البرامج التى تعتمد عل الاسس العلمية في مواجهة الظواهر المجتمعية كظاهرة التعاطى والادمان.

\section{هصطالحماهد التواسما}

المهارات الإجتماعية: يختلف تعريف المهارات الإجتماعية ويتباين من عالم إلى آخر،

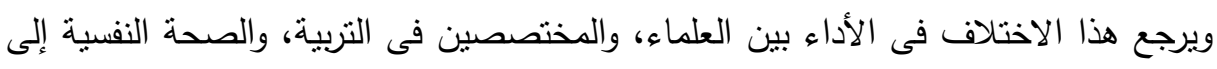
إختلاف المواقف الإجتماعية وما يحدث فيها من تفاعل لتحقيق الهدف المنشود وبناء على الهين إدراك الفرد للمواقف الذى يواجهه وذللك على إعتبار أن المهارات الاجتماعية بأنها قدرة الفرد على الإدراك بالمواقف المختلفة ومعرفتها من خلال ترجمتها إلى سلوكيات معينة مما يترتب

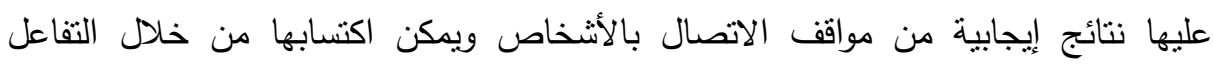

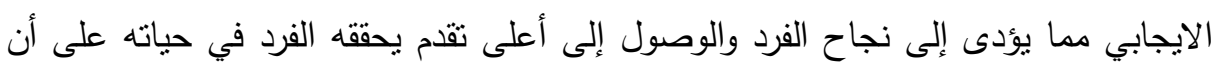


يكون هناك استعداد فطري وينمو هذا الاستعداد من خلال التعلم والتدريب والممارسة حتى يتم

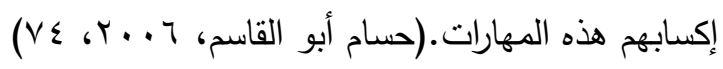

الإدمان: هو حالة تتشأ من التعاطي المستمر لعقار معين، حالة تتشأ من تفاعل الجسم مع

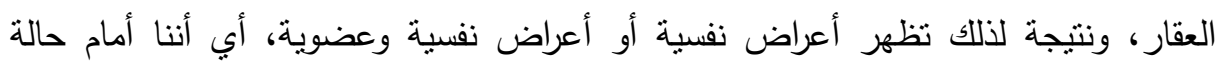
مرضية لها أعراض، وتتسم بسلوك أساسي، وهو الرغبة القهرية التي لا تقاوم في حالة

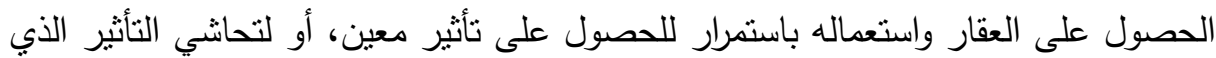

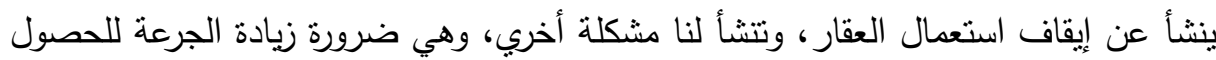
على نفس التأثير أو الحصول على التأثير المرغوب فيه.كل هذا ينشأ من سوء استعمال Substance use العقار، ولذلك يطلق على تلك الحالات اضطرابات استعمال الدواء

الاعتماد: حسب تعريف هيئة الصحة العالمية لشئون الاعتماد على العقاقير - هو حالة نفسية، وأحيانًا جسمية تتتج عن تفاعل بين كائن حي، وبين أحد العقاقير ، وتتضمن هذه الحالة

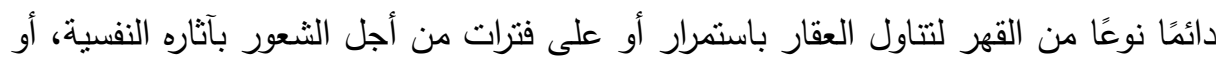

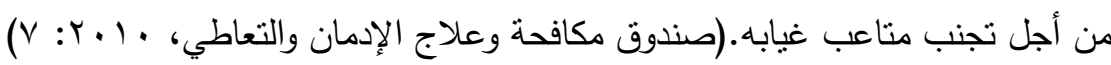
المتغيرات النفسية: يشير مفهوم المتغيرات النفسية فى هذه الدراسة إلي مجمل الخصائص التص النفسية الثابتة نسبياً المرتبطة بالجانب الانفعالي، والتي تميز الفرد عن الآخرين، ويتم التعبير عنها من خلال درجة الفرد على المقاييس المستخدمة فى هذه الدراسة. المتغيرات الاجتماعية: هي تلك المتغيرات المرتبطة بالظروف الاجتماعيبة التي تحيط بالفرد، وتلعب دور كبير فى تحديد سلوكياته مع الجماعة، وفى تفاعله مع المجتمع الذي

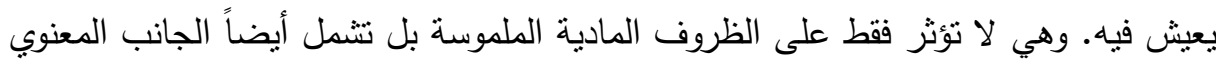
للبيئة كالثقافة والتعليم والأفكار السائدة. وهذه الدراسة تتحصر على على بعض هذه المتغيرات المتصلة ببيئة الفرد مثل (حجم الاسرة، والمستوي الاقتصادي الثقافي، والجنس). 
المراهقة: فتره عواصف وشده تكتنفها الأزمات النفسية وتسودها المعاناة والإحباط والصراع

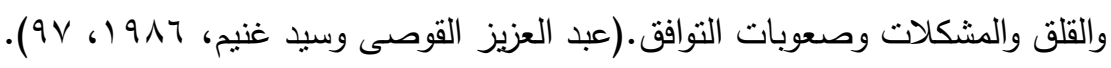

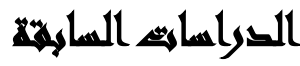

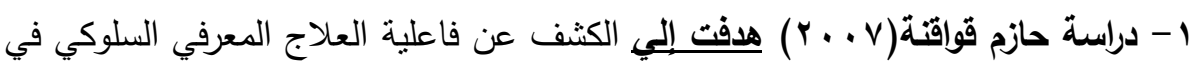
تتمية المهارات الاجتماعية وخفض القلق والاكتئاب لدى مدمني المخدرات، وقد اختيرت

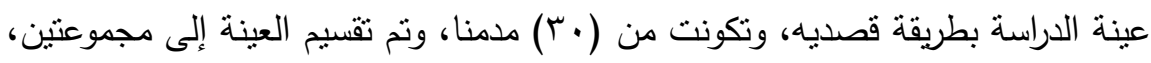

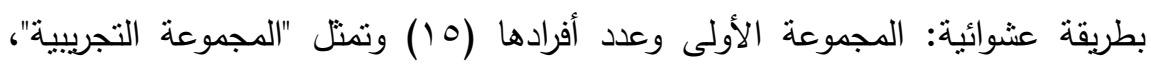

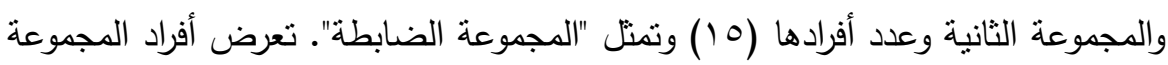

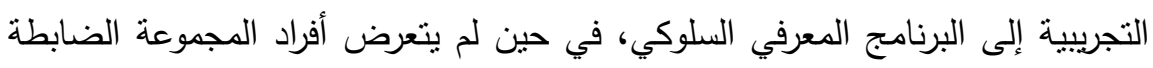

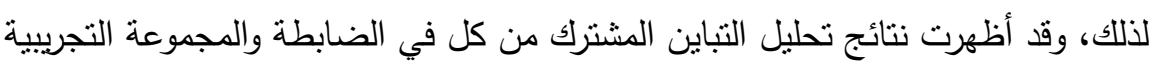
المجموعة نتائج بين (0. . •) عند مستوى دلالة إحصائيًا دالة فروق وجود، (ANOVA)

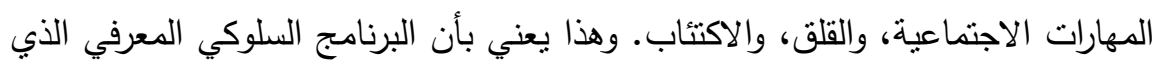

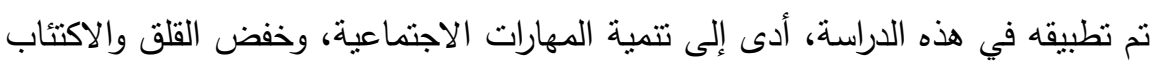
لاى أفراد المجموعة التجريبية.

Y - قام كل من (حاجي هادولي وزاير وأليدوست ويوراندي Khajehdaluee M, Zavar A, Alidoust M, Pourandi R., 2013)

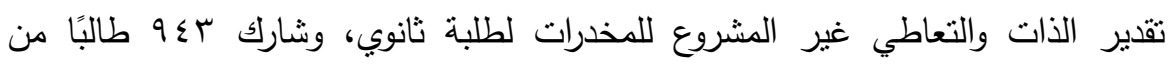

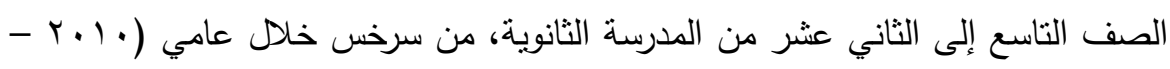

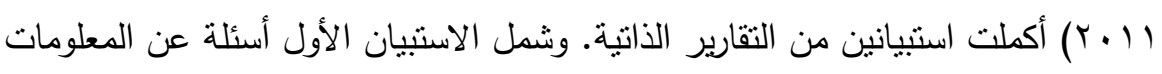

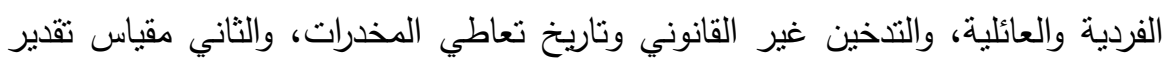

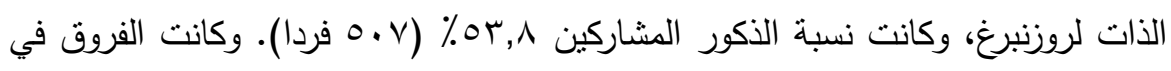
مقياس روزنبرغ التقة بالنفس بين الطلاب الذين لم تستخدم أي مادة وأولئك الذين لديهم تاريخ من التدخين أو تعاطي المخدرات منل الهيروين وحبوب منع الحمل، والكحول، نبات

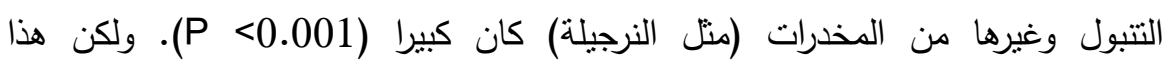

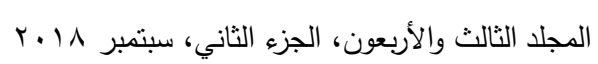


الاختلاف لم يكن كبيرا للماريجوانا (الحشيش) والأفيون. الفرق من متوسط درجات تقدير

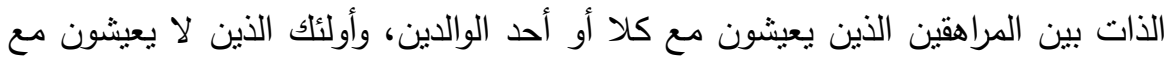

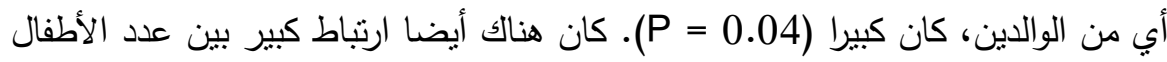
في النتيجة الأسرة واحترام الذات. وقد أظهرت الدراسة الحالية علاقة ذات دلانلة إلإنة إحصائية

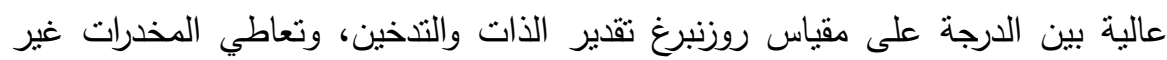

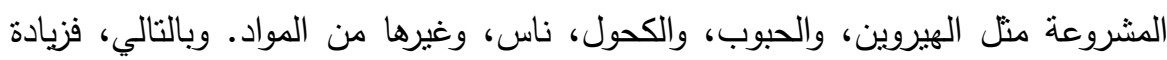

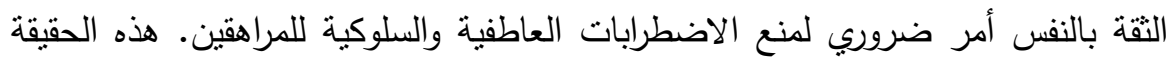
يمكن أن تدلنا على النهج الجديدة في الوقاية من للتنخين وتعاطي المخدرات لدى الدي

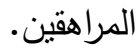

Yeganeh Yavaria \& Marzieh Arefi قام ياجنيه يافاري ومرذيه العريفي 2014: دراسة هدفت إلي مقارنة أنماط حل المشكلات لاي عينة من المدمنين وغير المدمنين في المرحلة العمرية (•r-r.r) في أصفهان، وهدفت هذه الدراسة إلي المقارنة بين عينتين مدمنين وغير مدمنين حيث شملت العينة التجريبية (المدمنين) على ( · ( ) شخص و(V • ( ) غير مدمنين من مركز علاج الإدمان في مستشفي أمين بأصفهان، وتخ

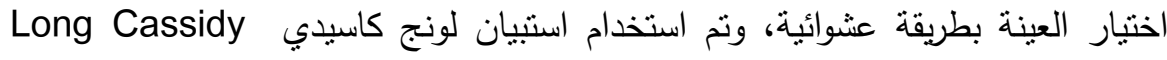
لمعرفة الفروق في حل المشكلات بين المجموعتين، وقد تم استخدام التحليل الإحصائي SPSS وق أوضحت النتائج انه لا توجد فروق دالة بين المجموعتين في استبيان حل المشكلات بين المجموعتين.

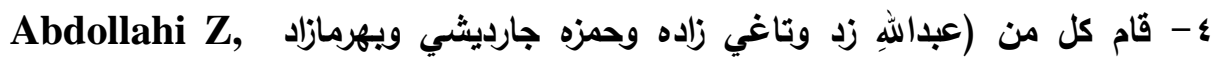
Taghizadeh F, Hamzehgardeshi Z \& Bahramzad O, 2014) العلاقة بين معدلات انتكاس الإدمان والكفاءة الذاتية في متعاطي المخدرات بالحقن بمركز

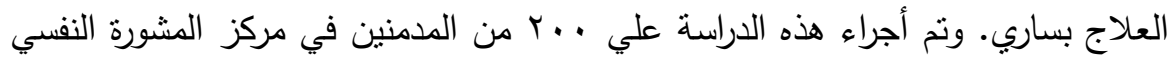

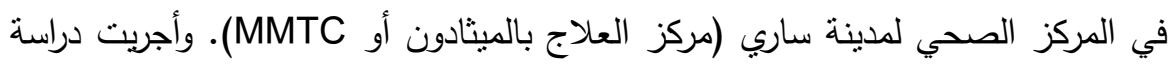

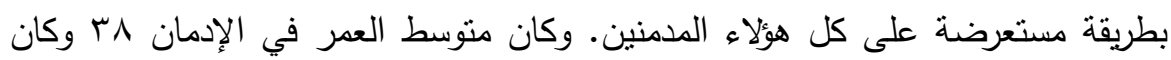




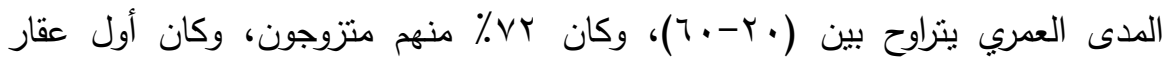
يستخدم هو الأفيون. وكل منهم كان معه تجربة مع الانتكاس مرة واحدة علي الأقل.

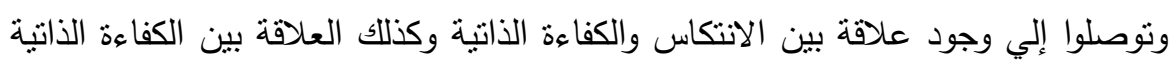

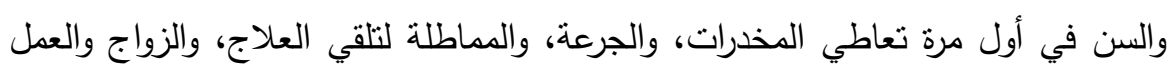
والمشكلات التي تواجهرم وسوء استغلال الوقت وكانت كلها ذات دلات دلالة إحصائية.

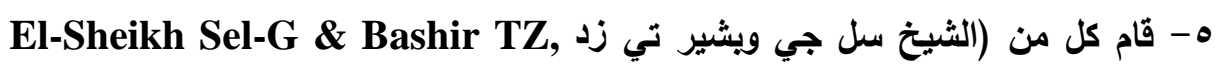

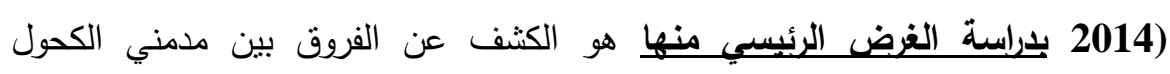

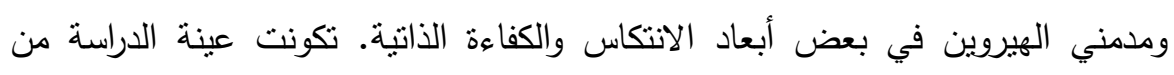
.11 من الذكور من مرضى القسم الداخلي بمستشفى الأمل بجدة بالمملكة العربية.

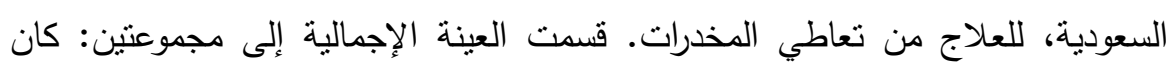

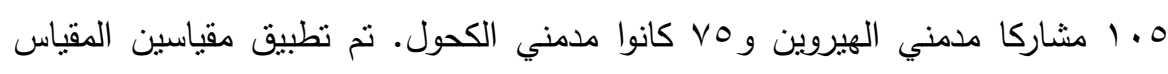
inventory of drug taking ( الأول كان يهدف لحصر مواقف تعاطي المخدرات situational confidence (SCQ)\} ومقياس التقة الظرفية (situations (IDTS) qquestionnaire الهيروين ذات دلالة عالية على مقياس IDTS مقارنة مع عينة المشروبات الكحولية، في

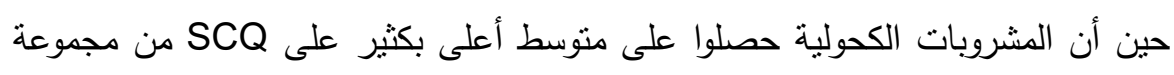

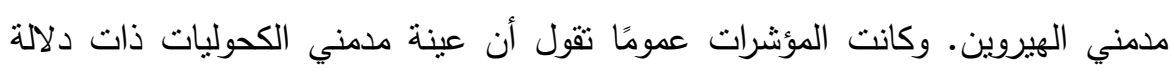
إحصائية منخفضة عن عينة مدمني الهيروين في الدرجات الكلية على المقياسين. وعلاوة على ذلك، تشبير النتائج إلى أن أعلى مخاطر الانتكاس هي المشاعر السلبية الفية، واختبار

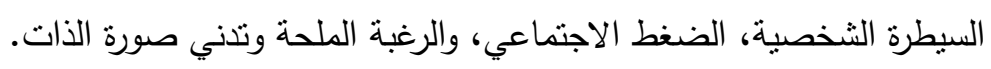

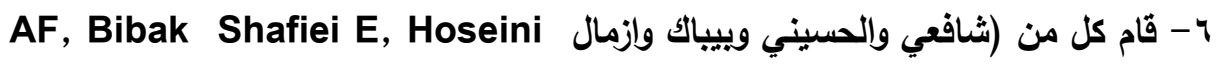
A \& Azmal M, 2014) المدمنين المحولين للعلاج من تعاطي المخدرات في محافظة "بوشهر" هذه الدراسة وصفية

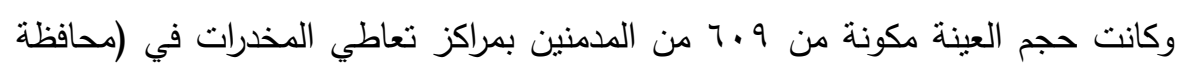
بوشهر). وقد استخدم "مقياس مارلات IDTS للمخدرات". استخدمت الدراسة الإحصاء

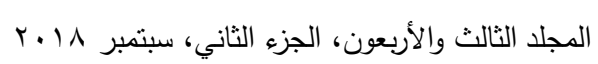




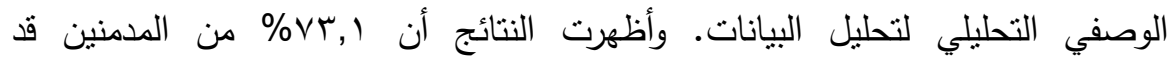

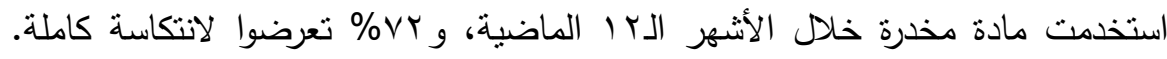

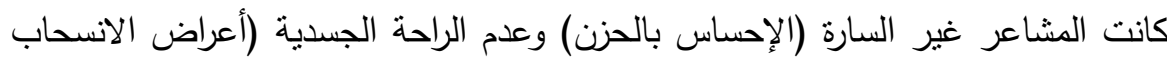
الجسدية) أهم أسباب الانتكاس واختبار السيطرة (التعافي المزيف) والمتعة الحسية كانوا من الأسباب القليلة المهوة، وكانت العوامل الثخصية أيضا لها دور كبير في هذا الصدد. وكانت مقترحات الدراسة أنه ينبغي الاهنمام بالأسباب التي تؤدي إلى الانتكاسة والعودة العابة مرة أخرى للمخدرات. تعقيب: يتضح من النظرة العامة إلى الدراسات السابقة اتفاق هذه الدراسات في بعض الأهداف واختلافها في البعض الآخر، حيث اتفقت كثير من هذه الدراسات في الاتجاه نحو السيطرة على الاعتماد على المواد النفسية والتعافي منه بوصفه عائق للتفاعل السوي مع الآخرين وبحث العلاقة بين وجود هذا العائق (الاعتماد) والاتجاه نحو تحسين بعض المهارات الاجتماعية، وتختلف هذه الدراسات على نوعية العلاج المقدم للتعافي من الاعتماد على المواد النفسية كل على حسب توجهه النظري والفلسفي.

تباينت الدراسات المعروضة سابقًا في حجم العينة التي اشتملت عليها نباينًا شديدًا حيث تعدت العينة في دراسات الآلاف في حين لم تصل في البعض الآخر إلى عشرة مبحوثين وقدا فئل

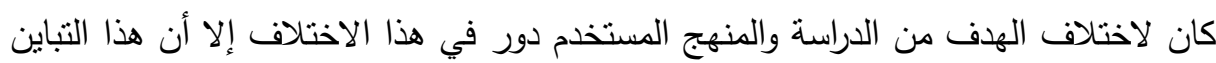

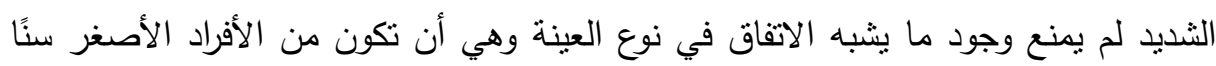

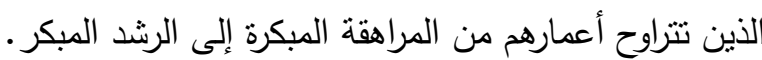

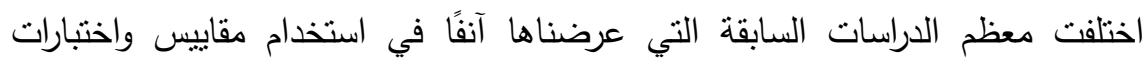
نفسية لقياس المتغيرات التي تننتها بالدراسة ولكنها كلها اعتمدت على النموذج العلمي في التهاتي قياس الظاهرة موضع القياس فمنها من استخدم استمارة البيانات الأولية ومقاييس (استبيان لجمع المعلومات عن سلوك تعاطى العقاقير، ومقاييس متعددة لقياس الهستيريا والانطواء الاجتماعي والثعور بالوحدة والاكتئاب والعلاقات الاجتماعية والقلق، واستمارة بيانات خاصة،

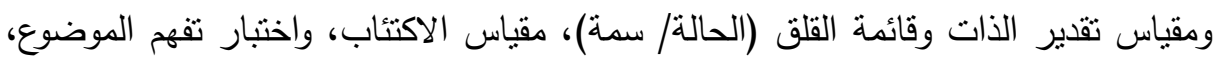


واستمارة المقابلة الكلينكية، والمقابلة الحرة الطليقة، ومقياس تقدير الذات، ومقياس الثعور بالوحدة، واختبار تقدير الذات واختبار أيزنك للثخصية، ومقياس الاتجاه نحو تعاطي المخدرات.

ويتضح من نتائج الدراسات السابقة بشكل عام ومن البحث القومي للإدمان تراجع سن

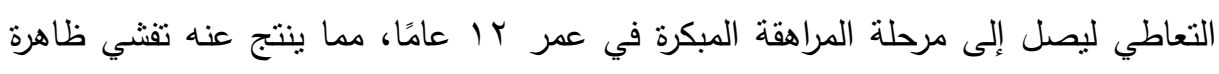

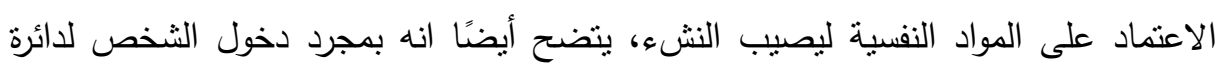

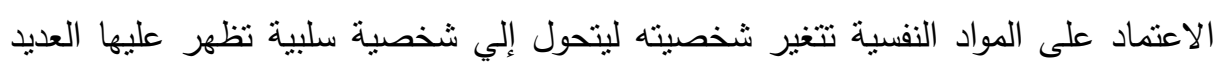

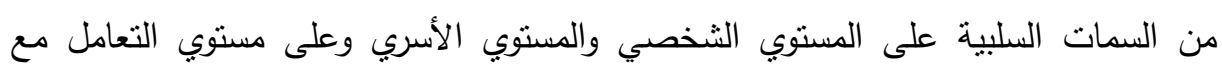
الآخرين.

وقد استفادت الباحثون في الدراسة الحالية من الاراسات السابقة في النقاط التالية:

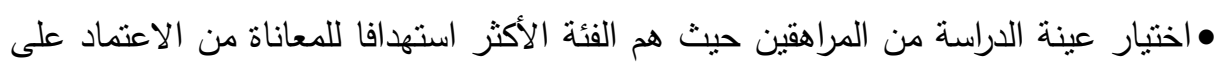
المواد النفسية. •اختيار الذكور بوصفهم أكثر استهدافا للتعاطي من الإناث.

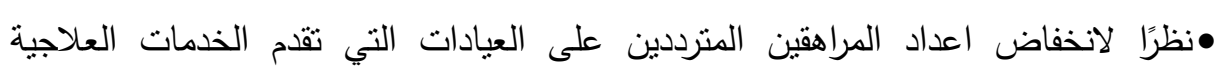
والتأهيلية فإن عدد عينة الدراسة الحالية يعد مناسباً من الناحية الاجرائية والنطبيقية.

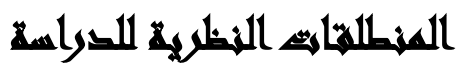

العوامل الوراثية: وتثمل دراسات التبني والتوائم:

أ.دراسات التبني: لقد دعمت دراسات التبني دور العوامل الوراثية في نطور اضطراب دراب الاعتماد على الكحوليات (Carbbe \& Harris, 1991)، ومن هذه الدراسات دراسات أجريت في السبعينات بواسطة باحثين مختلفين في كل من الدنمارك والسويد والولايات

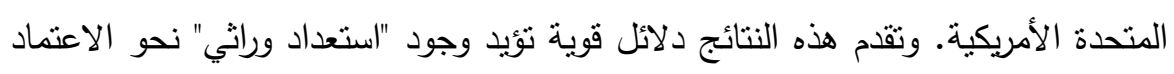

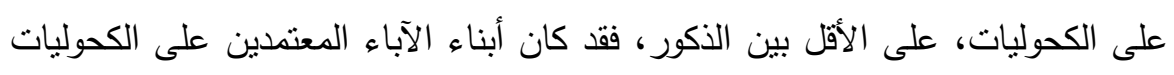

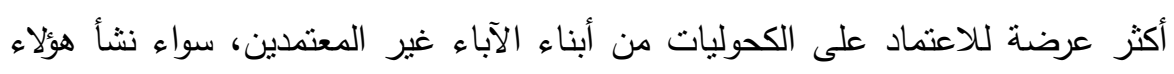
الأبناء مع آبائهم البيولوجيين (الآباء بالولادة) أو مع أباء بالتبني غير لاءلئ معتمدين ولكن حين

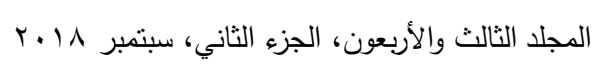


أجريت على آباء بالتبني معتمدين، أعطت الدراسة نتائج مثتاقضة Blum \&

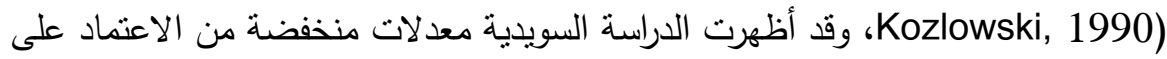

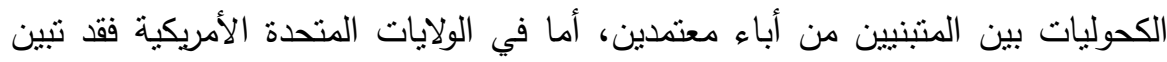

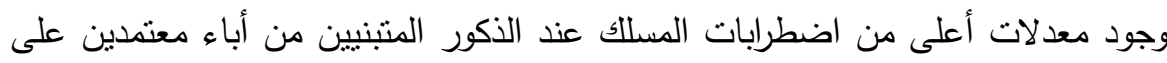

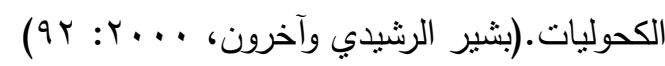
وقد دعت أيضًا دراسات التبني دور العوامل الوراثية في التهيؤ للاعتماد على المواد النفسية، وقد أجري العديد من الدراسات في هذا الصدد، وتثثير نتائجها جميعًا إلى تأكيد دور العامل الوراثي، حيث أن الأبناء الذين ينحدرون من آباء معتمدين على المواد النفسية يزيد فيدي

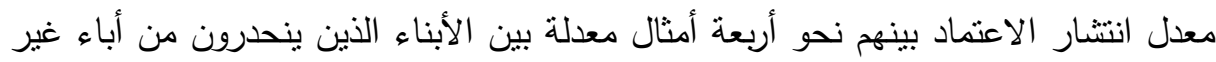

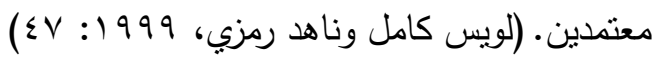
ب.دراسات التوائم: تتمنل في الدراسات التي أجريت على التوائم المتماثلة وغير المتماثلة، وقد تبين في دراسة أجريت في هذه الصدد أن انتشار تعاطي الكحوليات داخل أزواج

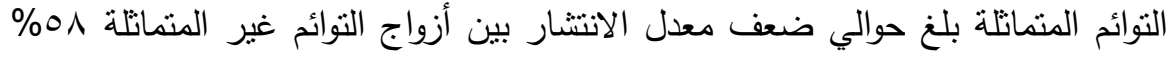

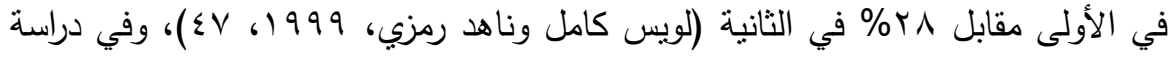

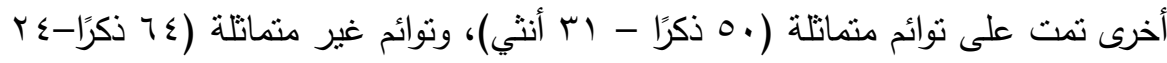
أنثي) تنين أن التوائم المتمانلة من الذكور تختلف عن الذئم الذكور غير المتماثلة في شدة وتكرار الاعتماد على الكحوليات والمواد النفسية بينما الإناث المتمانلة وغير المتماثلة منساويات في احتمالية التعرض لاضطراب الاعتماد على المواد النفسية، ولكن الإناث

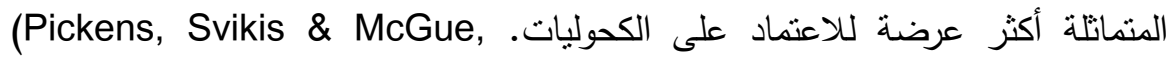
ا ـ التفسيرات الحيوية: تتعدد التفسيرات التي طُرحت بشأن العوامل والآليات الجسمية التي ترتبط بالإدمان، ومن أبرز تلك التفسيرات:

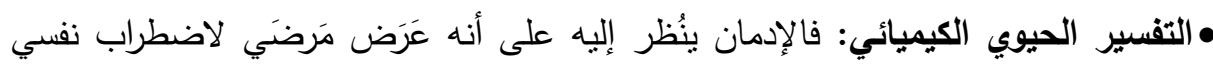
تؤدي فيه مادتان منشطتان تحتويان على الكولين (الكولين Choline مادة منبهة تحتوى لإنه 
على فيتامين وتعمل على أداء الكبد لوظيفته وعلى منع تكس الدهن في الكبد)، يطلق

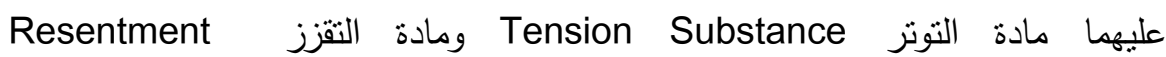
Substance

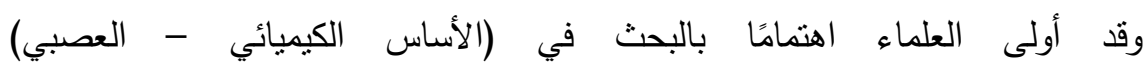
Dopamine Reward الذي يكمن في نظام (الإثابة للاوبامين Neurochemical Basis (System الكوكايين في تتشبط آليات الدوبامين، ثم استخدموا عقاقير أخرى متعددة كالمنبهات منل الأمفيتامين والنيكوتين، والمسكنات مثل الكحوليات، وفى ذللك يبدي بعض الباحثين تحفظًا إزاء

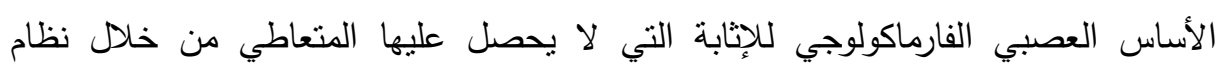

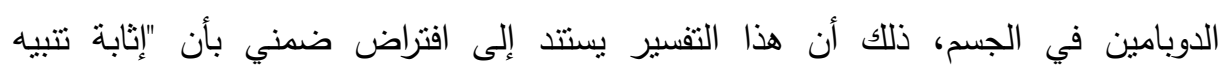

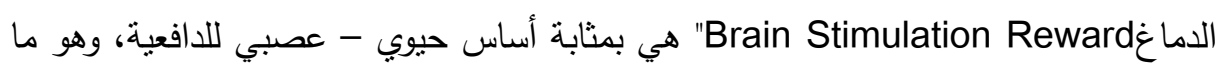
لم تقم عليه البيئة العلمية الكافية.(Lieman. J \& Cooper. S, 1989: 93) •نظريات أمراض الدماغ Brain Pathology: تذهب هذه النظريات في بعض الأحيان إلى

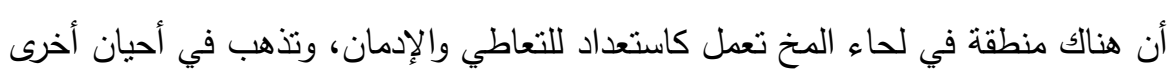

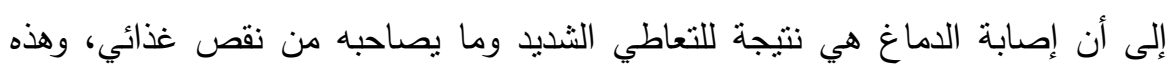

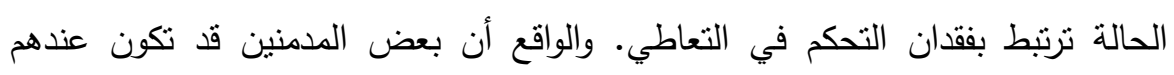

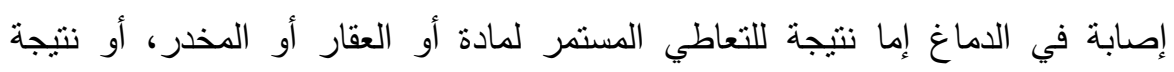
للجرعات الزائدة والتعاطي الكثيف أو نتيجة للحوادث التي تقع لهم وهم تحت تأثثير العقار

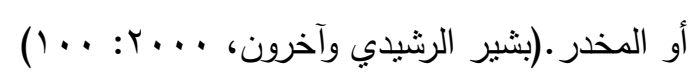

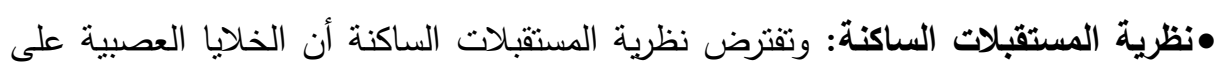
جدارها نوعان من المستقبلات:

الأول: نوع نشط ويسمي بالنوع الدوائي وهو الذي ينشط عند وصول نول العقار إليه والتصاقه به،

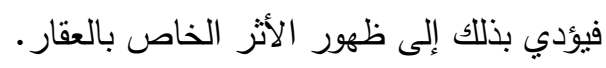

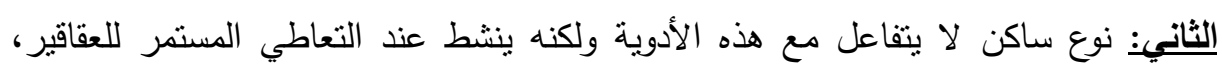

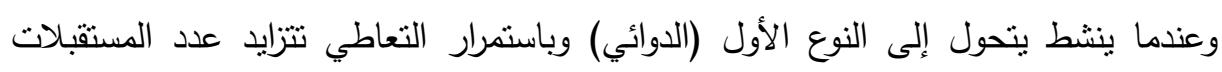

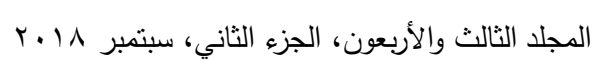


الدوائية، وذلك نتيجة زيادة الجرعات التي كان بتتاولها الفرد من أجل تحقيق نفس المفعول الذي كان يحصل عليه من جرعات صغيرة تنتاسب وعدد المستقبلات الدوائية، وهذه الزيادة في الجرعة لإحداث نفس الأثر تسمي بظاهرة التحمل، أما عند التوقف المفاجئ عن تعاطي العقار

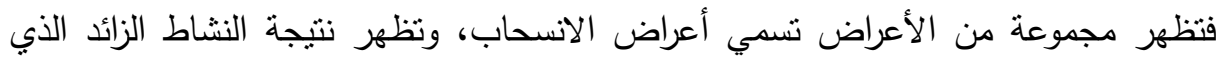

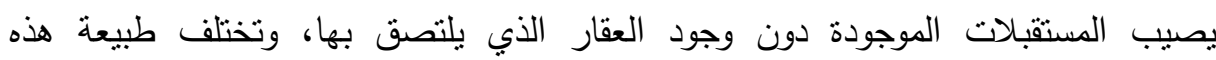

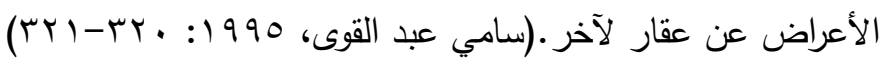

r. التفسيرات النفسية: كثف الباحثّن في العوامل والعمليات البيولوجية والوراثية للإدمان عن نتائج ذات قيمة ولا شك في تقسير ظاهرة الإدمان في بعض جوانبها، وثمة عدد من Inheritability هؤلاء الباحثين أنفسه يحذرون من التبسيط الزائد في تقسير القابلية لوراثة

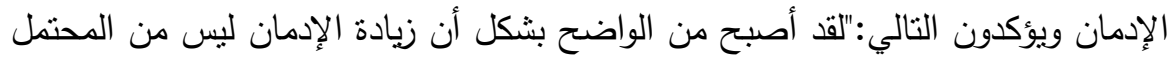
أن يكون نتيجة لعامل واحد بيولوجي أو سلوكي. فمرض الإدمان يعكس في الحقيقة التفاعلات المركبة لعوامل الاستعداد البيولوجي والسلوكية في ارتباطها بالعوامل الاستعداد

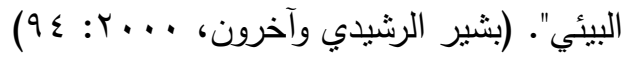

•نظريات الثخصية: كان لتفسير الإدمان من منظور الثخصية تأثير عميق على النظرة

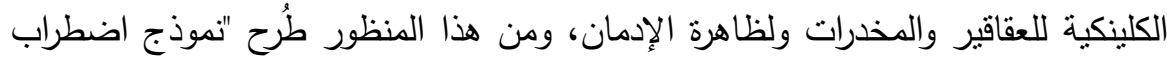
الثخصية" كإطار تقسيري لإدمان العقاقير والمخدرات، ويتضح هذا المنحي في "الدليل

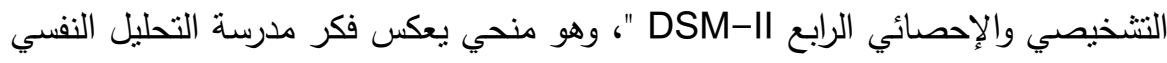
عن "عصاب الخلق"Character Neurosis: فالأشخاص الذين يصيرون مدمنين لديهم استعداد للإدمان بسبب خصائص شخصياتهم، ويعتبر الإدمان ذاته عرضًا من أعراض مناض

هذه المشكلة الكامنة.(Gossop, M., 1994: 374-375) وقد شاع في تفسير الإدمان وصف لشخصية المدمن بالظاهرة ذاتها فيما يعرف بـ

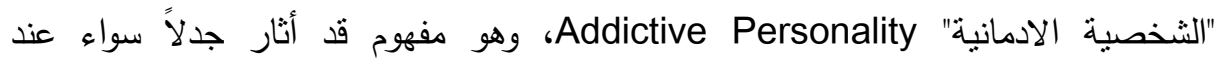
الاختصاصبين أو غير الاختصاصبين، ذلك أنه لا يوجد نمط فريد للشخصية يسبق الإدمان

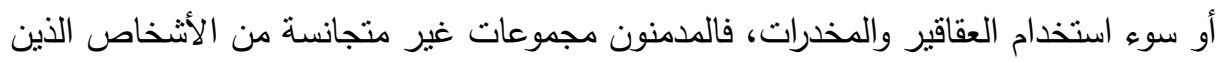


يختلفون من حيث النوع والعمر والطبقة الاجتماعية والعقاقير المستخدمة وأساليب التعاطي والأعراض النفسية المرضية المصاحبة وهكذا، ناهيك عن التباين الثاسع في الاتجاهات المجتمعية والقانونية نحو المجموعات المختلفة من المتعاطين ونحو العقاقير المختلفة والأساليب المختلفة للتعاطي. ولهذا فإنه في مقابل "الثخصية الادمانية" الفريدة والكلية يُطرح مفهوم عن بعض "السمات السلوكية الاستعدادية "Predisposing Behavior Traits وهذه ولهابه السمات قد تكون كامنة في عديد من الثخصيات، ومن هذه السمات السلوكية التي وُجد أنها

$$
\text { ترتبط بنمو سوء استخدام العقاقير والمخدرات: }
$$

$$
\text { •صعوبات في التحكم في الاندفاعات (السلوك الاندفاعي). }
$$

•صعوبات في مواجهة الضغوط، بما فيها من مشكلات تحمل الاندات الإحباط. • أنماط سلبية- اعنمادية السلوك.

• التمركز حول الذات مع أنماط سلوكية أنانية ذاتية (متل كثرة المطالب والاستحواذية).

• سلوك مضاد المجتمع.

• نموذج التوقع Expectancy Model (النموذج المعرفي): تعتمد هذه الفئة من نماذج

النظريات السلوكية في تفسير الإدمان على العوامل المعرفية، وعلى توقع وجود علاقة

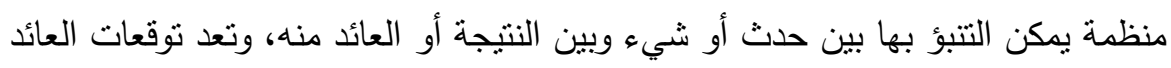

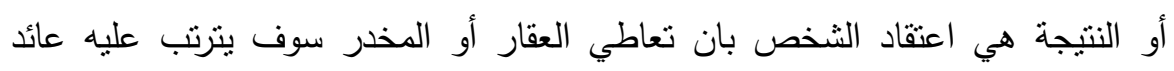
مرغوب أو نتيجة مرجوة، وتكون التوقعات منها على أنا تخفف التوتر ، وتحدث لذهة أذها وتزيد الجنسية، والعدوانية، والتوكيدية الاجنماعية. ومن الواضح أن هذه التوفئ التوقعات يجري تعلمها

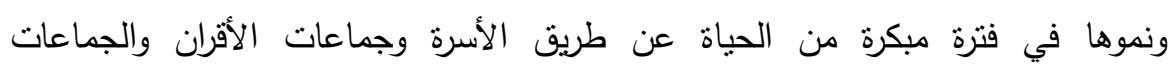

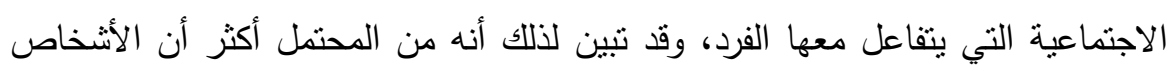
المدمنين الذين يتوقعون أن التعاطي يمدهم بتأثثرات إيجابية مرغوبة ويزيد من التوكيدية

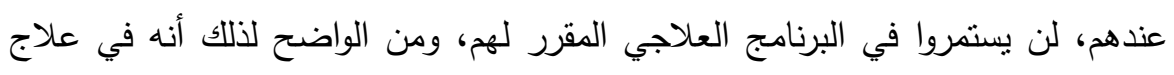

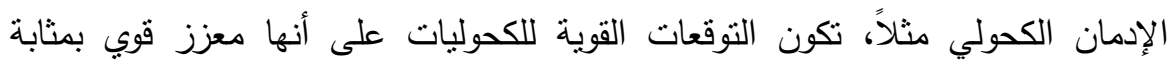

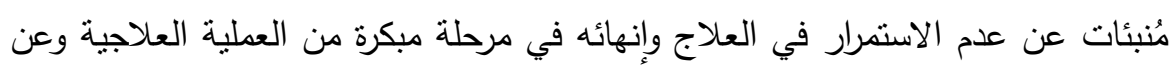

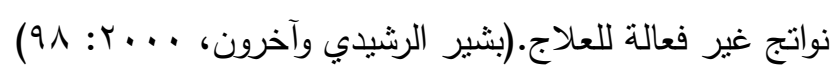

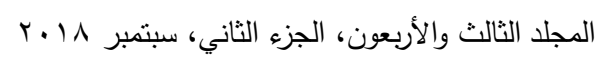




\section{إجباءاهي القراسما}

استخدمت الباحثون في هذه الدراسة المنهج الوصفي، وذللك بنطبيق مقياس المهارات الاجتماعية لاي المراهقين المعتمدين علي الإدمان. تم اختيار العينة بالطريقة القصدية، حيث تم اختيار العينة من المعتمدين المترددين على عيادات الخط الساخن التابع لصندوق مكافحة وعلاج الادمان أما مصدر البيانات فقد تم الحصول عليها من مصدرين هما:

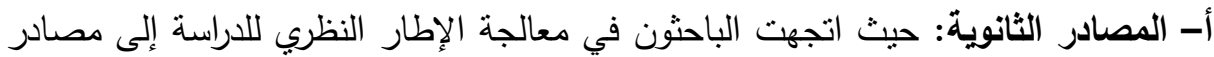

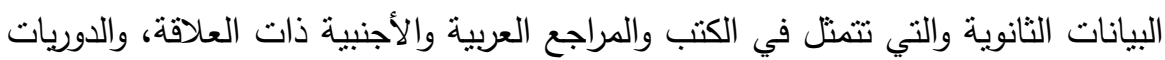
والمقالات والتقارير، والأبحاث والدراسات السابقة التي تتاولت موضوع الدارسة، والبحث

$$
\text { والمطالعة في مواقع الإنترنت المختلفة. }
$$

ب- المصادر الأولية: وتتمنل في جمع البيانات الأولية ميدانياً، وذلك من خلال استخدام

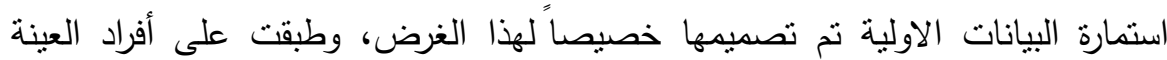

$$
\text { لجمع البيانات المطلوبة. }
$$

ميدان الاراسة: نم إجراء هذه الدراسة على المراهقين المعتمدين بعيادات الخط الساخن التابع لصندوق مكافحة وعلاج الادمان والتعاطي. شروط العينة: نم اختيار العينة بالطريقة القصدية، حيث نم اختيار العينة من المعتمدين المترددين على عيادات الخط الساخن التابع لصندوق مكافحة وعلاج الادمان، كما اعتمدت الباحثون على عدة شروط في اختيار العينة وذلك لزيادة في إحكام وضبط الدراسة الحالية (قدر المسنطاع) وكانت كالتالي: • من حيث العدد: تتكون العينة من (•0) مراهق معتمد على المواد النفسية وذلك من خلال

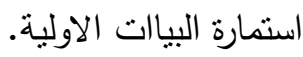
• من حيث النوع: أن يكون جميع أفراد العينة من الذكور، لأن الإناث خلال مرحلة المراهقة (من خلال خبرة الباحثون في المجال) يكون التركيز عليهن أكثر من الذكور في المتابعة والرقابة خوفًا عليهن، كما أن البيانات الواردة في ليجال (صندوق مكافحة وعلاج الإدمان 


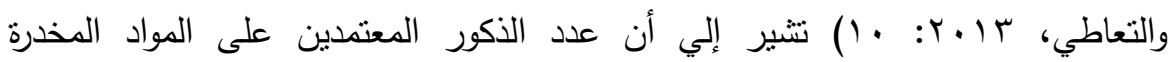

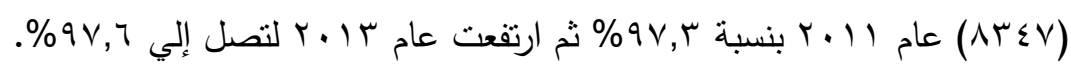

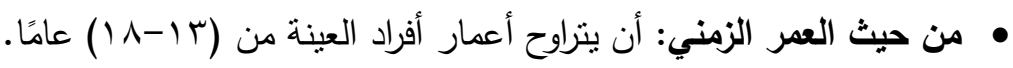

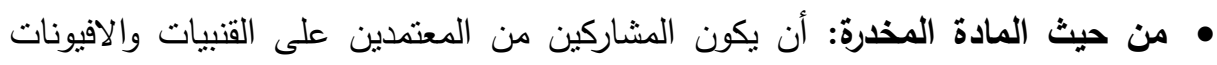

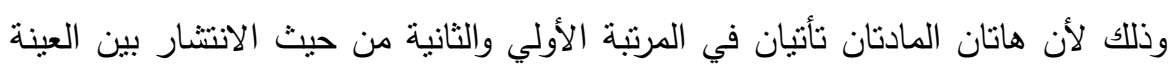
التي طبق عليها البحث القومي وفق البيانات الواردة في (البحث القومي للإدمان،

$\cdot(r \cdot 10$

• أخذ موافقة الأهل على استمارة الموافقة المستتيرة، وذلك لإشتراك نجلهم في الدراسة (لمعرفة حقوقهم ولضمان الاستمرارية)، وأن يكون مقيمًا مع أسرته أو أحد أفرادها.

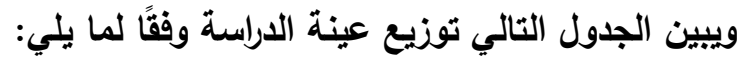

\begin{tabular}{|c|c|c|c|c|}
\hline المادة المخدرة & درجة الأكاء & النسبة\%\% & عدد الآَرَاد & المرحلة العمريـة \\
\hline قنبيات - افيونات & 90 & $\% r$. & 1. & -11 \\
\hline قنبيات - افيونات & $9 V$ & $\% r$. & 1. & $-1 \leqslant$ \\
\hline قنبيات - افيونات & 90 & $\% r$. & 1. & -10 \\
\hline قنبيات - افيونات & $9 \leq$ & $\%$ \%. & 1. & -17 \\
\hline قنبيات - افيونات & 91 & $\% r$. & 1. & $1 \wedge-1 V$ \\
\hline
\end{tabular}

من الجدول (1) يتضح أن توزيع المشاركين منساوً داخل المراحل العمرية وكذللك نجد

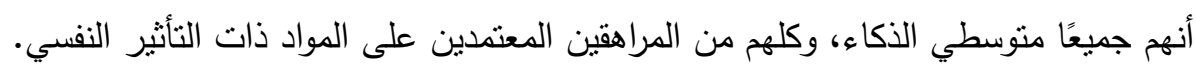

\section{أشواهت التصواسم}

$$
\text { • • استمارة البيانات الاولية (من اعداد الباحثون). }
$$

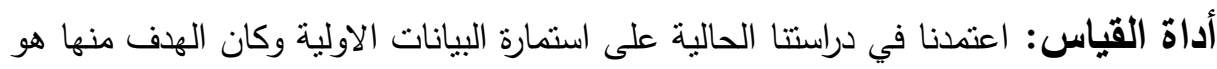
جمع معلومات كيفية عن المدمنين بهدف استبعاد الحالات التي لا تتطبق عليها شروط العينة وكذللك الإلمام بجميع جوانب الثخصية بالإضافة إلى تيسير عمل علاقة علاجية مع المدمنين ومقياس المهارات الاجتماعية لقياس درجة المهارات (توكيد الذات وحل المشكلات وادارة الغضب) عند المدمنين. كما يتكون هذا المقياس من r مهارات فرعية وهما مهارة توكيد الذات ورله

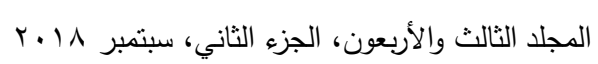


ومهارة ادارة الغضب ومهارة حل المشكلات ويبلغ عدد بنوده Vo بند.أما البدائل التي تم استعمالها في المقياس فهي بدائل واحدة وهيه بدائل: موافق تماما، موافق، احيانا ،غير بوده موافق، غير موافق تماما. صدق وثبات ادوات الدراسة ( ) الصدق Validity: نم حساب الصدق لمقياس المهارات الحياتية من خلال:

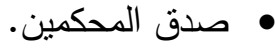

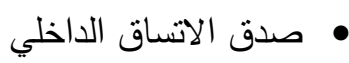
أ- صدق المحكمين: عن طريق مجموعة من الخبراء والمختصين (المحكمين) في المجال، وذلك للحكم على مدي تمثيل بنود المقياس لمحتوي المتغير موضع القياس، ومدي اتفاقها

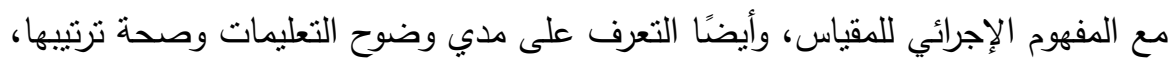
وما مدي دقة ووضوح ألفاظ بنود المقياس المصاغة، وما إذا كانت البنود مناسبة للمرحلة العمرية التي سيطبق عليها أم لا. قام الباحث بعرض المقياس في صورته الأولية على عدد من السادة المحكمين (تسعة) أساتذة من أساتذة علم النفس والطب النفسي المتخصصين بالجامعات المصرية، وذللك لاستطلاع آرائهم والاستفادة منها في الحكم على جودة المقياس ومدى تمثنيل بنوده للمحتوي ومدي ملاءمة بنود المقياس للمفهوم الذي أعد من أجله، وقد كان الاتفاق بين آراء المحكمين

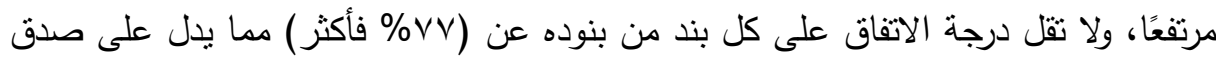
تكوين الأداة. وفيما يلي مقياس المهارات الحياتية بعد استبعاد البنود التي لم يتفق عليها السادة

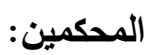

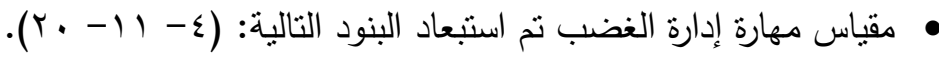

$$
\begin{aligned}
& \text { • مقياس مهارة حل المشكلات نم استبعاد البند التالي: (9). }
\end{aligned}
$$

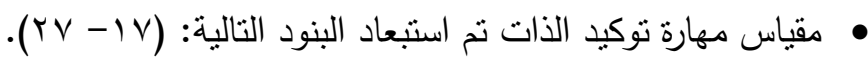

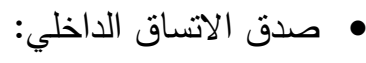


ونم ذللك من خلال حساب معامل ارتباط بيرسون وكانت النتائج كالتالي: جدول(ץ): صدق الاتساق الداخلي لمقياس المهارات الاجتماعية(درجة ارتباط كل مهارة

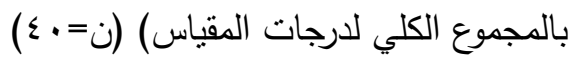

\begin{tabular}{|c|c|c|}
\hline إجمالى المقياس & \multicolumn{2}{|c|}{ المتغيرات } \\
\hline$(* *) \cdot, 9 Y \leqslant$ & معامل ارتباط بيرسون & \\
\hline., .1 & الدلالة المعنوبة & مهارة إدارة الغضب \\
\hline$(* *) \cdot, 970$ & معامل ارتباط بيرسون & $y<: 111$ \\
\hline$\cdot, ., 1$ & الدلالة المعنوية & مهارة حل المسدرك \\
\hline$(* *) \cdot, 9 Y V$ & معامل ارتباط بيرسون & - Mill \\
\hline$\cdot, ., 1$ & الدلالة المعنوية & مهاره يوحيب الدات \\
\hline
\end{tabular}

من جدول (r) نجد أن هناك ارتباطات موجبة وقوية ودالة إحصائيًا لمكونات المقياس اله

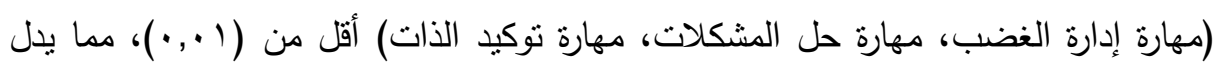
علي صدق الاتساق الداخلي لمقياس المهارات الحياتية.

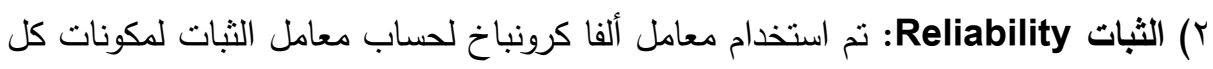
مقياس فرعي ولحساب معامل الثبات لكل مقياس فرعي للمقياس الكلي وكانت النتائج كالتالي: ماني

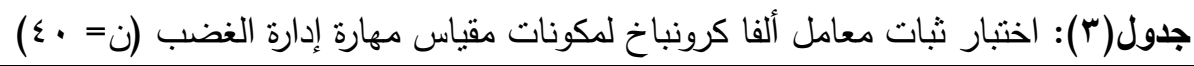

\begin{tabular}{|c|c|c|}
\hline عدد العبارات & معامل الثبات & المكون \\
\hline 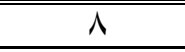 & $\cdot, V Y T$ & مكون تكرار نوبات الغضب \\
\hline 10 & $\cdot, \mathrm{V} \leqslant 1$ & مكون كيفية التعامل مع الغضب \\
\hline
\end{tabular}

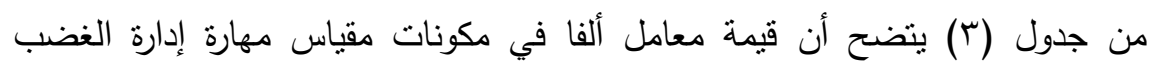

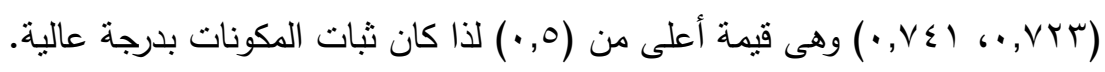

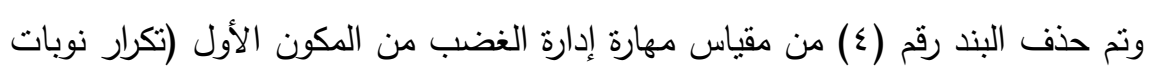
الغضب) وذلك لأن درجة ثباته كانت غير دالة.

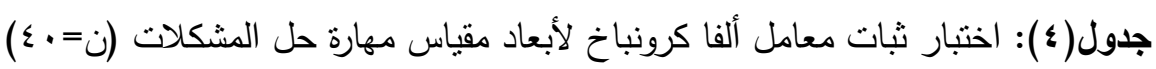

\begin{tabular}{|c|c|c|}
\hline عدد العبارات & معامل الثبات & المكون \\
\hline$\overline{\varepsilon \varepsilon}$ & $\cdot, V Y$. & مكون الاتجاه نحو المشكلة \\
\hline r & $\cdot, \wedge \leqslant \Gamma$ & مكون تحديد وصياغة المشكلة \\
\hline $\bar{V}$ & $\cdot, \mathrm{V} \vee \varepsilon$ & مكون وضع الحلول البديلة \\
\hline $\bar{v}$ & $\cdot, \mathrm{V} / \mathrm{I}$ & مكون التقييم \\
\hline$\varepsilon$ & $\cdot, \Lambda) \mathrm{V}$ & مكون آخذ القرار \\
\hline
\end{tabular}

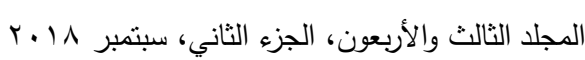


من جدول (ع) يتضح أن قيمة معامل ألفا لمكونات مقياس مهارة حل المشكلات

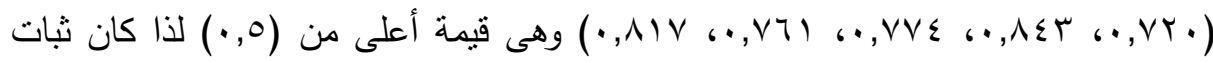

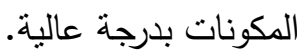

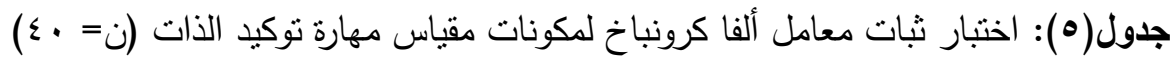

\begin{tabular}{|c|c|c|}
\hline عدد العبارات & معامل الثبات & المكون \\
\hline 0 & $\cdot, V T r$ & مكون التعبير عن الذات دون الحساسية \\
\hline 7 & $\cdot, \mathrm{V} \circ \mathrm{V}$ & مكون التوكيد في التعامل في المواقف الحياتية \\
\hline Tr & $\cdot, V \leqslant Y$ & المواجهة في المواقف العامة \\
\hline
\end{tabular}

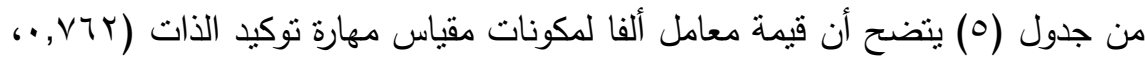

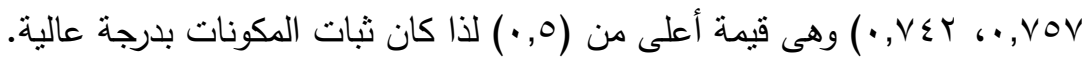

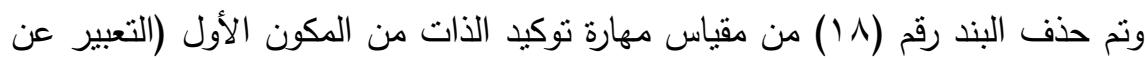
الذات دون حساسية) وذلك لأن درجة ثباته كانت غير دالة.

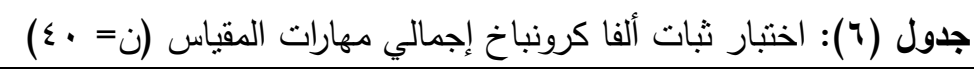

\begin{tabular}{|c|c|c|}
\hline عدد العبارات & معامل الثبات & المقاييس الفرعية \\
\hline$\overline{T \xi}$ &., $9 \cdot r$ & إدارة الغضب \\
\hline FT & $\cdot, \wedge Y_{0}$ & حل المشكلات \\
\hline Tr & $\cdot, 107$ & توكيد الذات \\
\hline
\end{tabular}

من جدول (T) يتضح أن قيمة معامل ألفا للمقاييس الفرعية للمهارات لمقياس المهارات

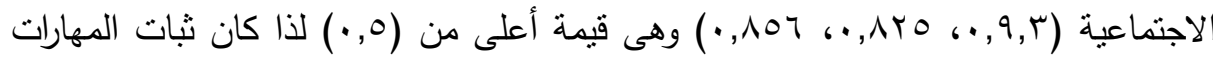

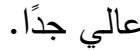

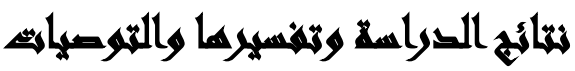

ينص الفرض الأول علي أنه "تتوجد فروق ذات دلالة احصائية بين درجات افراد عينة الدراسة (إعدادي) وأفراد عينة الدراسة (ثانوي) علي مهارة إدارة الغضب".وللتحقق من صحة

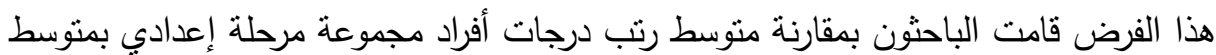
رتب أفراد مجموعة مرحلة ثانوي، وذلك علي مقياس المهارات الاجتماعية المستخدم في لهربه الدراسة الحالية، واستخدمت الباحثون اختبار مان وينتي Mann Whitney اللابارامتري 
للكثف عن دلالة الفروق بين المجموعتين. ويوضح الجدول (V) ما توصلت إليه الدراسة من نتائج في هذا الصدد. جدول(V): اختبار مان ويتتي لتوضيح الفروق بين درجات عينة الدراسة (إعدادي) وأفراد عينة

\begin{tabular}{|c|c|c|c|c|c|c|c|}
\hline & & & & مَ الغضب & مهارة إدا & ة تثانوي & \\
\hline المعنوية & ل ل ميتني & ويلكسون & Z & مجموع & متربط & التطبيق & أبعاد المقياس \\
\hline - V & 5190 & $0<<0$ & 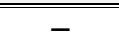 & $0 \leq \leqslant, 0$ & $r I, V \wedge$ & ثنانوي & \\
\hline$\cdot, \cdot v$ & $17,0$. & 022 & $1, \wedge \cdot 9$ & $V V_{\cdot, 0}$ & Yq,Yr & إعدادي & لحرار \\
\hline & & & - & or $\cdot, 0$ & YI,YY & ثانوي & إدارة الغضب \\
\hline$\cdot, \cdot \Sigma$ & $r .0,0$. & Or., & $r, \cdot V \wedge$ & $V \leq \varepsilon, 0$ & $r q, \vee \wedge$ & إعدادي & مع "الغضية التعامل) \\
\hline & & & - & OYO & YI & ثانوي & مهارة إدارة \\
\hline$\cdot, \cdot 1$ & 10 & $0,0, \ldots$ & $r, 110$ & vo. & $\mu$. & إعدادي & الغضب \\
\hline
\end{tabular}

تفسير نتائج الفرض الأول كمياً: من الجدول السابق لدراسة الفروق بين درجات أفراد

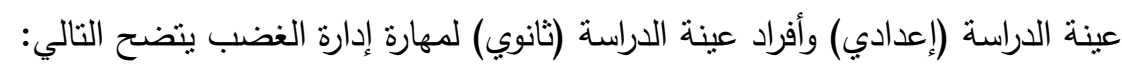

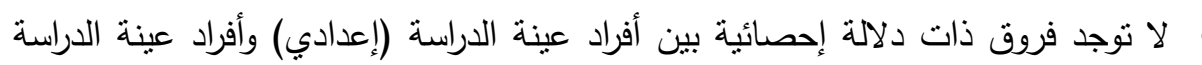

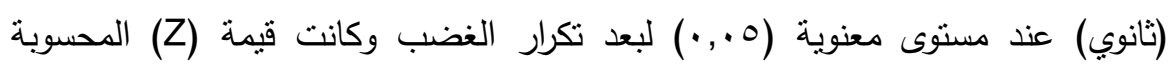

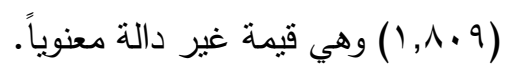
توجد فروق ذات دلالة إحصائية بين أفراد عينة الدراسة (إعدادي) وأفراد عينة الدراسة

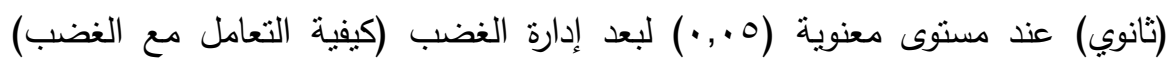

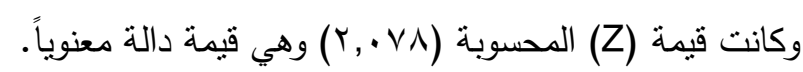

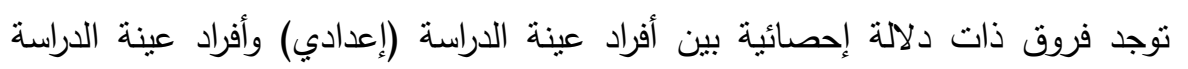

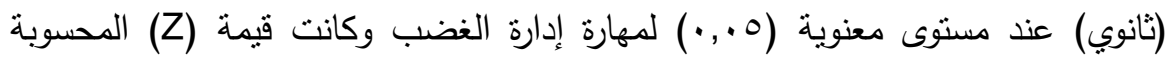

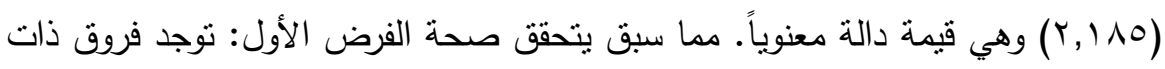
دلالة احصائية بين درجات عينة الدراسة (إعدادي) وأفراد عينة الدراسة (ثانوي) لمهارة 
عرض نتائج الفرض الثاني: ينص الفرض الثاني على أنه: "توجد فروق ذات دلالة احصائية بين درجات أفراد عينة الدراسة (إعدادي) وأفراد عينة الدراسة (ثانوي) لمهارة حل

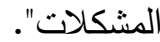

جدول(^): اختبار مان ويتتي لتوضيح الفروق بين درجات عينة الدراسة (إعدادي) وأفراد عينة الدراسة (ثانوي) لمهارة حل المشكلات

\begin{tabular}{|c|c|c|c|c|c|c|c|}
\hline المعنوية & ويتتي مان & ويلكسون & $\mathbf{Z}$ & الرجموع & متوبط & العينة & أبعاد المقياس \\
\hline \multirow{2}{*}{$\cdot, \cdot \wedge$} & \multirow{2}{*}{ YYI,O. } & \multirow{2}{*}{$0 \leqslant 7,0}$. & \multirow{2}{*}{$\overline{1,-}$} & $0 \leqslant 7,0$ & YI,AT & ثانوي & \multirow{2}{*}{ الاتجاه نحو } \\
\hline & & & & $V Y \wedge, 0$ & $r q, 1 \leq$ & إعدادي & \\
\hline \multirow{2}{*}{$\cdot r$} & \multirow{2}{*}{ ros, , . } & \multirow{2}{*}{ O^r,.. } & \multirow{2}{*}{$\begin{array}{c}- \\
1, \cdot 7 V\end{array}$} & $0 \wedge r$ & Tr,Mr & ثانوي & \multirow{2}{*}{ تحديد وصياغة } \\
\hline & & & & 794 & $r V, T \Lambda$ & إعدادي & \\
\hline \multirow{2}{*}{$\cdot, \cdot 7$} & \multirow{2}{*}{ r) $\leq, \ldots$} & \multirow{2}{*}{ orq,... } & \multirow{2}{*}{1,919} & org & $Y 1,07$ & ثنانوي & \multirow{2}{*}{ وضع الحبلة البلة } \\
\hline & & & & VTr & $r q, \leqslant \varepsilon$ & إعدادي & \\
\hline \multirow{2}{*}{$\cdot, 0$} & \multirow{2}{*}{$r V V, \ldots$} & \multirow{2}{*}{$r \cdot r, \ldots$} & \multirow{2}{*}{$\begin{array}{c}- \\
., 794\end{array}$} & $7 . Y$ & $r \varepsilon, \cdot \Lambda$ & ثانوي & \multirow{2}{*}{ التقييم } \\
\hline & & & & $T V T$ & $r 7,9 r$ & إعدادي & \\
\hline \multirow{2}{*}{$\cdot, \varepsilon$} & \multirow{2}{*}{$r V Y, \ldots$} & \multirow{2}{*}{$09 \vee, \ldots$} & \multirow{2}{*}{$\begin{array}{c}- \\
\cdot, \vee \vee q r\end{array}$} & $09 \mathrm{~V}$ & $r r, \wedge \Lambda$ & ثانوي & \multirow{2}{*}{ اتخاذ القرار } \\
\hline & & & & TVA & $r V, I T$ & إعدادي & \\
\hline \multirow{2}{*}{$\cdot, r$} & \multirow{2}{*}{$r r q, \ldots$} & \multirow{2}{*}{$07 \varepsilon, \ldots$} & \multirow{2}{*}{$\begin{array}{c}- \\
1, \varepsilon r V\end{array}$} & $07 \varepsilon$ & YY,OT & ثانوي & \multirow{2}{*}{ مهارة حلت } \\
\hline & & & & (1) & $r \wedge, \Sigma \Sigma$ & إعدادي & \\
\hline
\end{tabular}

تفسير نتائج الفرض الثاني كمياً: من الجدول السابق لدراسة الفروق بين درجات أفراد

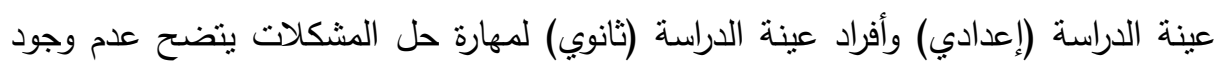

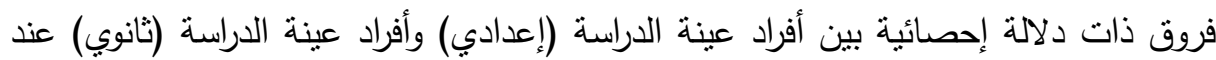

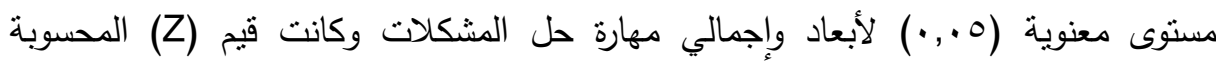

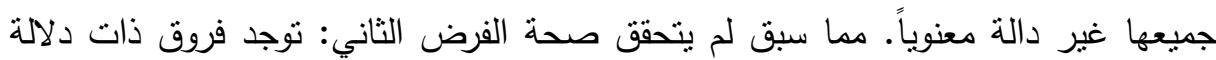

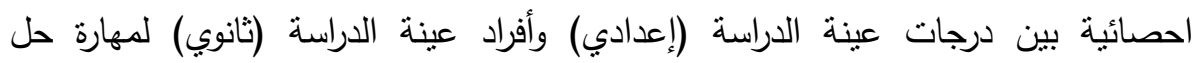

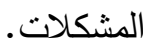


عرض نتائج الفرض الثالث: ينص الفرض الثالث على أنه: "توجد فروق ذات دلالة احصائية بين درجات أفراد عينة الدراسة (إعدادي) وأفراد عينة الدراسة (ثانوي) لمهارة نوكيد

جدول(9): اختبار مان ويتتي لتوضيح الفروق بين درجات عينة الدراسة (إعدادي) وأفراد عينة

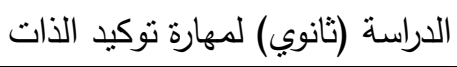

\begin{tabular}{|c|c|c|c|c|c|c|c|}
\hline المعنوية & و ل ماني & ويلكسون W & $\mathbf{Z}$ & مجموع & متوسط الرتب & العينة & أبعاد المقياس \\
\hline \multirow{2}{*}{$\cdot, 97$} & \multirow{2}{*}{$r 1 \cdot, .}$. & \multirow{2}{*}{ 7ro,... } & \multirow{2}{*}{$\begin{array}{c}- \\
.,, \leq 99\end{array}$} & $7 \varepsilon$. & $r 0,7$ & ثانوي & \multirow{2}{*}{ التعبير عناسية الذات } \\
\hline & & & & 7100 & Yo, $\varepsilon$ & إعدادي & \\
\hline \multirow[b]{2}{*}{$\cdot, 1$} & \multirow[b]{2}{*}{ rrr,.. } & \multirow[b]{2}{*}{$00 \wedge, \cdots$} & \multirow{2}{*}{1,004} & 001 & $r Y, r Y$ & ثانوي & \multirow{2}{*}{ التوكيد فيى المواقعامل } \\
\hline & & & & VIV & $\curlyvee \wedge, \curlyvee \wedge$ & إعدادي & \\
\hline \multirow{2}{*}{$\cdot, r$} & \multirow{2}{*}{$r \leqslant r, \cdot \cdot$} & \multirow{2}{*}{$071, \ldots$} & \multirow{2}{*}{ 1, } & 071 & $r Y, V r$ & ثانوبي & \multirow{2}{*}{ تجنب المواجهة فيى العامة } \\
\hline & & & & $V \cdot V$ & $r \wedge, r \wedge$ & إعدادي & \\
\hline \multirow{2}{*}{$\cdot, \cdot 9$} & \multirow{2}{*}{$r Y \leq, O}$. & \multirow{2}{*}{ T.Y, . } & \multirow{2}{*}{$\stackrel{-}{1, \times 11}$} & $0 \leqslant 9,0$ & Y),91 & ثنانوي & \multirow{2}{*}{ مهارة توكيد الذات } \\
\hline & & & & VYo,0 & $r q, \cdot r$ & إعدادي & \\
\hline
\end{tabular}

تفسير نتائج الفرض الثالث كمياً: من الجدول السابق لدراسة الفروق بين درجات أفراد عينة الدراسة (إعدادي) وأفراد عينة الدراسة (ثانوي) لمهارة نوكيد الذات ينضح عدم وجود

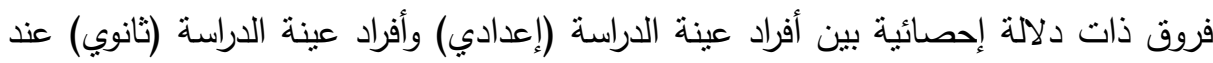
مستوى معنوية (0. . •) لأبعاد وإجمالي مهارة توكيد الذات وكانت قيم (Z) المحسوبة جميعها

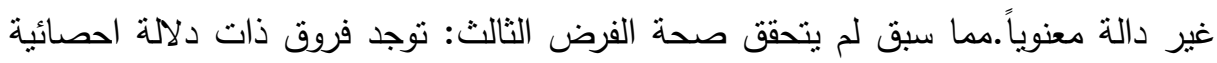
بين درجات عينة الدراسة (إعدادي) وأفراد عينة الدراسة (ثنانوي) لمهارة نوكيد الذات.

\section{تموسياهي التصواسمة}

في ضوء النتائج التي نوصلت إليها توصى الدراسة عند وجود أي سلوك إدماني صادر من المراهق إتباع ما يلي:

• توجيه المراهق بطريقة غير مباشرة إلى أنشطة محببة ومناسبة لتدعيمه عندما يؤدى النشاط

بجدية.

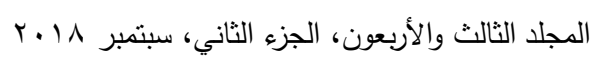




$$
\begin{aligned}
& \text { • تدريب المراهق المدمن على التعبير عن مشاعره تجاه أي مشكلة تواجهه حتى يتسنى عدم } \\
& \text { وقوعه فريسة لتلك المشكلة. } \\
& \text { • العمل على بناء برامج إرشاد جمعي لأسر المدمنين وذلك لأهمية دور الأسرة في علاج }
\end{aligned}
$$

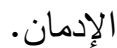

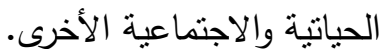

\section{المرالئ}

بشير الرشيدى وآخرون: سلسلة تشخيص الاضطرابات النفسية، اضطرابات تعاطى الإدمان

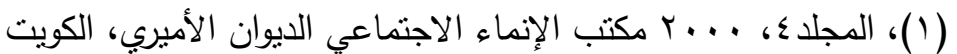

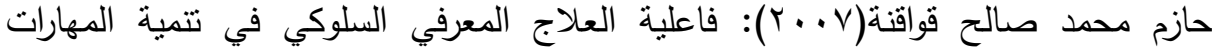

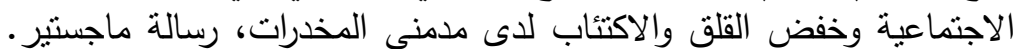

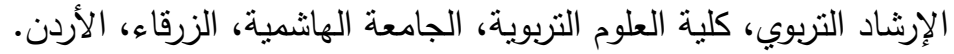

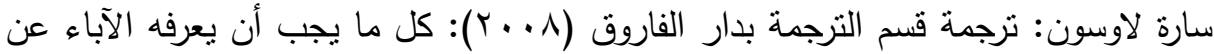
أبنائهم، طا، القاهرة: دار الفاروق للاستثمارات الثقافية.

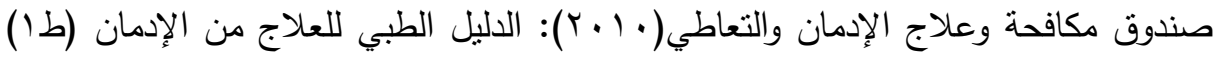

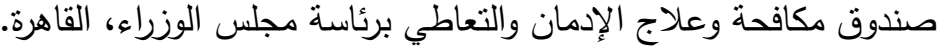

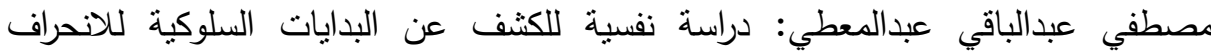

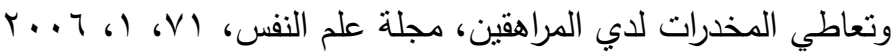

Abdollahi Z, Taghizadeh F, Hamzehgardeshi Z, Bahramzad O. (2014):

Relationship between addiction relapse and self-efficacy rates in injection drug users referred to Maintenance Therapy Center of Sari, Glob J Health Sci. 2014 Feb $28 ; 6(3)$

El-Sheikh Sel-G \& Bashir T. Z., (2014): High risk relapse situations and self-efficacy: comparison between alcoholics and heroin addicts, Addict Behav. 2014 Jun; 29(4).

Gossop, M. (1994): Drug and alcohol problems in S.J.E, Lindsay and G.E powell (eds), the handbook of clinical adult psychology, London and New York: Rutledge.

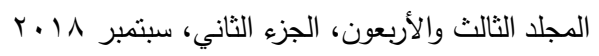


Khajehdaluee M, Zavar A, Alidoust M, Pourandi R. (2013): The relation of self-esteem and illegal drug usage in high school students, Iran Red Crescent Med J. Nov; 15 (11):e7682.

Shafiei E; Hoseini A F; Bibak A \& Azmal M. (2014): High risk situations predicting relapse in self-referred addicts to bushehr province substance abuse treatment centers, Int $\mathbf{J}$ High Risk Behav Addict. 2014 Jun 15; 3(2):e16381.

World Drug Report (2015): United Nations Office on Drugand Crime, United Nations (Vienna), New York, America.

Yeganeh Yavaria \& Marzieh Arefi (2014): Comparison of problemsolving styles among non-addict and addicted young adults (20-35 YEARS) in ISFAHAN, Indian J. Sci.Res.7(1).

\title{
THE PSYCHOLOGICAL AND SOCIAL VARIABLES ASSOCIATED WITH DEVELOPING SOCIAL SKILLS OF SAMLE OF ADDICTION TARGETED
}

\section{ADOLESCENTS}

Mahmoud, Hadeer, Sh. ${ }^{(1)}$; Karam El-Din, Laila, A. A. ${ }^{(2)}$ and Abdel Latif, R. A. ${ }^{(3)}$

1) Institute of Environmental Studies \& Research, Ain Shams University 2) Faculty of Post Graduate Childhood Studies, Ain Shams University. 3) Faculty of Social Work, Helwan University.

\begin{abstract}
The problem of substance abuse is a serious psycho-social problem that affects society in general and the individual in particular, with its negative psychological, social and economic consequences. The problem lies in the fact that it is spread out among children who represent a basic human force in society. The danger of this problem is
\end{abstract}

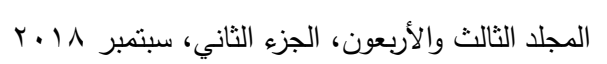


also that the individual no longer has a single drug, but he is taking more than one drug at the same time. The dependence between children and young people is one of the most widespread among all social strata of different cultures and beliefs. A father can in no way assert the fact that his son is one of those who cannot fall into the trap of relying on psychological materials. The current study relied on the following tools: Initial data form, social skills scale for the addressees and the actual sample: After verifying the validity and stability of the measuring instrument, the tools were applied to the sample of the study. This current study drives at identifying the psycho-social dimensions associated with development of social skills in addiction-targeted adolescents. The researchers use in this study the descriptive method. The sample is selected randomly from out-visitors on the Hot Line clinics associate to the Combat and Therapy Fund of Addiction. The sample consists of (50) male adolescents dependent on psychological drug-abuse, aged (13-18 years old). The present study uses these tools: primary data form - scale of social skills for addicts. After checking validity and reliability of measurement tool, it is applied on the study ample individuals, as researchers have administered (50) scales as the total number of the study sample individuals.

The most important results show and prove validity of the first hypothesis as: there are significant statistical differences between average scores of the study sample of (preparatory students) and the study ample of secondary students regarding the skill of anger control. The second hypothesis's validity is not proved as: there are significant statistical differences between average scores of the study sample of (preparatory) students and the study sample of (secondary) students regarding the skill of solving problems. The third hypothesis's validity is not also proved as: there are significant statistical differences between average scores of the study sample of (preparatory) students and the study sample of (secondary) students regarding the skill of selfactualization and guiding the adolescent indirectly to preferable activities and suitable for his sustenance when he fulfills them actively.

The researchers recommend the necessity for training for the adolescent-addict to express his feeling towards any problem he meets

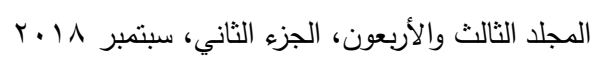


not fall as a victim to that problem; working as well on establishing a counseling collective programs that collect the addicts' families to guide them for the critical role a family plays in treating addiction.

Keywords: Social skills, Addiction, Adolescence. 